\title{
CRISIS DEL PARADIGMA REPRESENTATIVO Y PROPUESTAS DE IMPULSO DE LA DEMOCRACIA DIRECTA
}

CARLOS GARRIDO LÓPEZ 
1. RECESIÓN ECONÓMICA Y CRISIS DE LEGITIMIDAD DE LA DEMOCRACIA REPRESENTATIVA. 2. LAS CAUSAS DE LA CRISIS DEL PARADIGMA REPRESENTATIVO. 2.1. Ruptura del pacto social y democracia indignada. 2.2. Representación sin representados: la falta de receptividad de los representantes. 2.3. Las distorsiones en la configuración y la actualización de la representación. 2.3.1. Sistema electoral y desigualdad representativa. 2.3.2. Representatividad y funcionamiento oligárquico de los partidos políticos. 2.4. La cicatera regulación de las formas de democracia directa y participativa en el régimen constitucional español. 3. LAS PROPUESTAS DE IMPULSO DE LAS FORMAS DE DEMOCRACIA DIRECTA Y PARTICIPATIVA EN LA DOCTRINA Y EN LA X LEGISLATURA DE LAS CORTES GENERALES. 4. LA INICIATIVA LEGISLATIVA POPULAR COMO INSTRUMENTO PARTICIPATIVO. 4.1. El fracaso y la necesaria revisión de la iniciativa legislativa popular. 4.2. La reducción del número de firmas y de las materias excluidas. La apuesta por la iniciativa popular mixta o reforzada vinculada al referéndum. 5. LA FUNCIONALIDAD DEL REFERÉNDUM EN LAS DEMOCRACIAS REPRESENTATIVAS. 6. LA REGULACIÓN Y LA ESCASA PRÁCTICA DEL REFERÉNDUM EN ESPAÑA. DE NUEVO EL DEBATE SOBRE SUS RIESGOS. 7. LAS MODALIDADES DE REFERÉNDUM CUYA INCORPORACIÓN COMPLEMENTA Y CONTRAPESA LA DEMOCRACIA REPRESENTATIVA. LA PLURALIDAD DE SUJETOS LEGITIMADOS PARA INSTAR SU CONVOCATORIA. 8. CONSIDERACIONES FINALES. 


\title{
CRISIS DEL PARADIGMA REPRESENTATIVO Y PROPUESTAS DE IMPULSO DE LA DEMOCRACIA DIRECTA
}

\author{
CARLOS GARRIDO LÓPEZ ${ }^{1}$
}

\section{RECESIÓN ECONÓMICA Y CRISIS DE LEGITIMIDAD DE LA DEMOCRACIA REPRESENTATIVA}

En 2008, el balance que cabía hacer en España de la democracia representativa era muy positivo. El sistema electoral había dotado de legitimidad, representatividad y eficacia a las instituciones representativas. Había sido posible la formación de mayorías estables y la alternancia en el gobierno de diversas opciones políticas. Las principales instituciones representativas, como las Cortes Generales y las asambleas legislativas autonómicas, eran bien valoradas en las encuestas y estudios demoscópicos. Y los partidos políticos, cuya mediación actualiza la representación, también superaban el aprobado en el Barómetro sobre satisfacción institucional de noviembre 2008 elaborado por el Centro de Investigaciones Sociológicas (CIS) ${ }^{2}$. Tres años más tarde, en la primavera de 2011, las instituciones representativas entraron, sin embargo, en una profunda crisis de legitimidad. La recesión económica iniciada en EEUU hizo mella en España: el PIB decreció por encima del 3\%, el déficit público se disparó, el paro alcanzó la cifra del 21,6\% y se sucedieron los recortes en políticas públicas. Graves casos de corrupción salpicaron a las más altas instituciones, a cientos de cargos representativos y a los principales partidos políticos. En muy poco tiempo, el desánimo, la desconfianza y la indignación se generalizaron entre la ciudadanía.

Compartiendo estos sentimientos, días antes de las elecciones autonómicas y locales de mayo de 2011, diversos colectivos articularon un singular movimiento de protesta denominado $15 \mathrm{M}$ en alusión al día en que se iniciaron las movilizaciones.

1 Profesor titular de Derecho Constitucional. Departamento de Derecho Público. Universidad de Zaragoza. Calle Pedro Cerbuna s/n. 50009, Zaragoza. Email: cgarrido@unizar.es ORCID ID: https:// orcid.org/0000-0003-4741-7412

2 CIS (2008), Barómetro de noviembre (disponible en: http://datos.cis.es/pdf/Es2778mar_A.pdf).

(C) UNED. Revista de Derecho Político 
Inspirado en el ensayo Indignez-vous! de Stéphane Hessel, que en Francia había supuesto un aldabonazo contra la clase política «y los poderes financieros que lo acaparan todo» ${ }^{3}$, el movimiento logró sumar a las protestas, que se prolongaron con acampadas en lugares públicos, a miles de jóvenes, estudiantes y parados. Durante varios días, los congregados en la Puerta del Sol y en otras plazas de España corearon: «Que no, que no nos representan», «lo llaman democracia y no lo es» y «idemocracia real ya!». Estas proclamas sacudieron a los partidos políticos tradicionales, atrajeron la atención de los medios de comunicación y constituyeron para muchos ciudadanos una llamada a la reflexión, un revulsivo político, porque el $15 \mathrm{M}$ y las plataformas que le dieron continuidad no fueron sólo un movimiento de protesta, sino también de propuesta, que contribuyó a revitalizar el debate político sobre problemas latentes de nuestro sistema constitucional ${ }^{4}$.

En su manifiesto, acusaron a los representantes de no escuchar. La función de los representantes — denunciaban- debía ser llevar a las instituciones la voz de los representados, haciendo efectivo, con ello, su derecho a la participación política. En lugar de eso, los representantes atendían tan sólo los dictados de las élites y los grandes poderes económicos y utilizaban la representación obtenida tras las elecciones como un cheque en blanco. Por ello, el movimiento $15 \mathrm{M}$ y la plataforma «Democracia real» reclamaron la articulación de una democracia efectiva, lo que a su juicio exigía «referéndums vinculantes para las cuestiones de calado que modifican las condiciones de vida», «modificación de la Ley electoral para garantizar un sistema auténticamente representativo y proporcional que no discrimine ninguna voluntad ciudadana»y «democracia interna en los partidos políticos» ${ }^{5}$.

Los manifestantes no pasaron de ser una minoría, pero su diagnóstico sobre el funcionamiento de la democracia representativa halló eco en la sociedad española porque, según varias encuestas y el barómetro del CIS realizado en junio de 2011, el $78 \%$ de los ciudadanos consultados compartían las razones de los indignados ${ }^{6}$. Y dos años después, como subrayó un nuevo sondeo, el $63 \%$ de los españoles encuestados seguían compartiendo los argumentos expuestos por aquel movimiento ${ }^{7}$. Los ciudadanos, en suma, también percibían la tensión entre democracia y representación y consideraban que la elección no avala cualquier comportamiento y que la voluntad expresada en las urnas y la voluntad representada no coincidían, lo que evidenciaba

3 HESSEL, S. (2011). Indignez-vous!, Montpellier, Indigène Editions, p. 3.

4 PRESNO LINERA, M. A. (2013). El 15 M y la promesa de la política, Agenda Pública, pp. 60-70 (disponible en: https://www.academia.edu/6733756/El_15M_y_la_promesa_de_la_pol\%C3\%ADtica) y GUILLÉN LÓPEZ, E. (2014). «Las enseñanzas del 15-M (el léxico constitucional frente a la crisis de legitimidad)», en GUTIÉRREZ GUTIÉRREZ, I. (coord.). La democracia indignada: tensiones entre voluntad popular y representación política, Granada, Comares, pp. 8-27.

5 «Propuestas de ¡Democracia real ya!» en http://www.democraciarealya.es/documento-trasversal/.

6 CIS (2011). Barómetro de junio (disponible en http://datos.cis.es/pdf/Es2905mar_A.pdf).

7 CIS (2013), Barómetro de abril (http://datos.cis.es/pdf/Es2984mar_A.pdf) y $5^{\circ}$ Barómetro de confianza institucional, realizado por Metroscopia para el diario El País entre el 15 de junio y el 12 de julio de 2013 (https://elpais.com/politica/2013/08/24/actualidad/1377367465_986163.html). 
la distancia creciente entre el ideal y el logro de la representación política ${ }^{8}$. Una distancia que, bajo el impulso de otros movimientos de protesta, de nuevos partidos y de líderes outsiders, también había sido advertida por los ciudadanos de otros países europeos, al punto de sumir al paradigma representativo y los sistemas tradicionales de partidos en una seria crisis de legitimidad.

\section{LAS CAUSAS DE LA CRISIS DEL PARADIGMA REPRESENTATIVO}

A esta grave crisis del paradigma representativo se llegó por el efecto combinado de varios factores. Algunos de ellos eran coyunturales, propios del momento histórico tensionado por la globalización y la recesión económica. Otros, en cambio, son factores estructurales, comunes a la mayoría de las democracias representativas, y tienen que ver con la configuración jurídico-constitucional de las diversas formas de participación política, con el predominio participativo conferido a los representantes y con el escaso o nulo papel reconocido a la participación directa y semidirecta de los ciudadanos.

\subsection{Ruptura del pacto social y democracia indignada}

La primera causa de la crisis de la representación se hallaba en la incapacidad de los poderes públicos para detener, en el marco de la crisis, el menoscabo del bienestar material de los ciudadanos. Es sabido que legitimidad de las formas de gobierno no depende sólo de su origen, sino también de su eficacia para generar prosperidad, de sus resultados 9 . Y, desde este punto de vista, la democracia representativa había quedado inerme frente a la globalización económica y los nuevos factores reales de poder, que demandaban insistentemente el recorte de las conquistas sociales y el deterioro progresivo de las condiciones de trabajo. La recesión económica y la incapacidad del Estado para detener los procesos de desigualdad y empobrecimiento colectivo sacudieron los pilares de nuestra convivencia. La economía, carente de control, dominó la política e impuso la adopción de decisiones contrarias a los programas de gobierno y sin apoderamiento popular alguno. $\mathrm{Y}$ en este contexto de impotencia y de renuncia al ejercicio del poder político, el contrato tácito entre representantes y representados resultó cuestionado ${ }^{10}$.

8 Sobre la distancia entre el ideal y el logro de la representación, véase en el ámbito teórico PITKIN, H. F. (1985). El concepto de representación, Madrid, CEC, p. 267-269.

9 BOBBIO, N. (1964). «Sul principio di legittimità», Annali della Facolta Giuridica, Genova, p. 51-61.

10 BIGLINO CAMPOS, P. (2017). «Crisis de la representación, legitimidad de ejercicio y formas de responsabilidad», Revista de Derecho Político, 100, pp. 485-489, y GUILLÉN LÓPEZ, E. (2012). «El 
Como Gutiérrez afirmó en la obra colectiva La democracia indignada, la crisis económica hizo visibles las deficiencias de nuestras instituciones representativas, que habían sido contempladas con indulgencia o indiferencia en tiempos de bonanza, pero que resultaron intolerables cuando no ofrecieron respuesta alguna a los graves problemas cotidianos y adoptaron decisiones económicas críticas socialmente regresivas e impopulares ${ }^{11}$. Los ciudadanos reclamaron entonces no sólo resultados y la recuperación del bienestar perdido, sino también otras formas de hacer política y de conformar la voluntad general: receptividad de los representantes, transparencia, controles independientes y una democracia participativa de contrapeso que superara las limitaciones y deficiencias de la democracia representativa. Sánchez-Cuenca describió bien esta situación en su libro La impotencia democrática ${ }^{12}$, donde subrayó cómo la tensión entre democracia y capitalismo estaba asfixiando las vías tradicionales de participación y control políticos sin que otras vías pudieran abrirse paso ni materializarse.

\subsection{Representación sin representados: la falta de receptividad de los representantes}

Una segunda causa del cuestionamiento de la representación tenía que ver con la falta de receptividad de los representantes a las demandas y necesidades ciudadanas, cuyas decisiones durante la crisis económica no respondieron al interés inmediato de los representados, sino a los intereses y las urgencias de los mercados internacionales y de las grandes corporaciones y a las imposiciones del Fondo Monetario Internacional o de la Unión Europea. Al incumplir sus compromisos, los representantes dejaron de ser representativos y de hacer efectivo el derecho de participación de los ciudadanos.

El Parlamento representa y expresa la voluntad del Estado, pero las constituciones modernas atribuyen la soberanía nacional al pueblo, y eso — a juicio de los indignados- debía significar algo. En un Estado democrático no se representa en abstracto, como en el Estado liberal, porque el pueblo, formalizado como cuerpo electoral, puede hoy manifestar sus preferencias. Lo hace en las elecciones y puede hacerlo mediante la participación directa en referéndums y plebiscitos. La representación parlamentaria permite formalmente la creación y concreción de la voluntad general y, con ello, de la unidad del Estado, pero este artificio, en las democracias avanzadas, ya no es la

15-M desde la óptica del socialismo democrático», El Cronista del Estado Social y Democrático de Derecho, 30 , pp. 81-82 y 89.

11 GUTIÉRREZ GUTIÉRREZ, I. (2014). «Presentación», en GUTIÉRREZ GUTIÉRREZ, I. (coord.). La democracia indignada: tensiones entre voluntad popular y representación política, cit., p. XIV-XV. «La crisis —afirmó por su parte E. GUILLÉN LÓPEZ - es la brecha entre la sociedad y el Estado, la expresión normativa de lo fáctico, la muestra de la incapacidad del Estado para integrar el conflicto social aportando soluciones satisfactorias a los titulares de la soberanía». Cfr. «Las enseñanzas del 15-M (el léxico constitucional frente a la crisis de legitimidad)», cit., pp. 10-11.

12 SÁNCHEZ-CUENCA, I. (2014). La impotencia democrática. Sobre la crisis política de España, Madrid, Los Libros de la Catarata, pp. 165-189. 
única vía posible para la concreción de la voluntad de todos. La representación democrática debe ser, por tanto, algo más. Representar democráticamente no es sólo hacer presente jurídicamente lo ausente, sino hacer visibles a los representados, actuar en su interés de manera sensible ante ellos ${ }^{13}$. Ser representado no es solo votar y elegir representantes. No es sólo una delegación de autoridad. La representación democrática exige, además, reconocimiento y visibilidad. No es únicamente representación formal, sino también de contenidos. Debe haber receptividad a las demandas ciudadanas expresadas mediante elecciones, encuestas o manifestaciones. Y transparencia y rendición efectiva de cuentas de los representantes ${ }^{14}$. Lo contrario puede encubrir una forma moderna de usurpación. Y así ha sido vista la representación por una parte de los ciudadanos al quebrar su confianza y no sentirse representados. "Con la crisis —afirmó Guillén López-, ya no quedan ni ingenuos ni cínicos que afirmen sin sonrojo que el poder normativo real está en las instituciones llamadas a representar la voluntad general. Y los que salen a la calle dicen que no admiten más el engaño [...]. Reclaman que el poder esté donde los ciudadanos estén» ${ }^{15}$.

\subsection{Las distorsiones en la configuración y la actualización de la representación}

Junto a estos factores, en la crisis del paradigma representativo concurren algunas causas estructurales, siendo la primera de ellas el modo de configuración de los instrumentos fundamentales que permiten la actualización de la representación: el sistema electoral y los partidos políticos, cuya regulación y funcionamiento llevan tiempo cuestionados.

\subsubsection{Sistema electoral y desigualdad representativa}

Tras la proclama «No nos representan», se hallaba la denuncia de la desigualdad representativa del sistema electoral, que potencia la sobrerrepresentación parlamentaria de las dos fuerzas con mayor apoyo popular, reduce la representación de las minorías y dificulta la aparición y consolidación de nuevas formaciones políticas. La Ley Orgánica 5/1985, de 19 de junio, del Régimen Electoral General (LOREG) respeta el principio de proporcionalidad en los distritos, pero incumple dicho principio en el conjunto al permitir que el coste electoral por escaño, es decir el número de votos necesarios para lograr un diputado, sea tan distinto entre circunscripciones y

13 PITKIN, H. F. (1985). El concepto de representación, cit., p. 236.

14 SARTORI, G. (1999). «En defensa de la representación política», Claves de Razón Práctica, 91, pp. 2-6; Sobre la distinción entre la representación formal o institucional y la representación centrada en el contenido, BÖCKENFÖRDE, E.-W. (1993). «Democracia y representación. Crítica a la discusión actual sobre la democracia», en Estudios sobre el Estado de Derecho y la democracia, Madrid, Trotta, pp. 149-150.

15 GUILLÉN LÓPEZ, E. (2014). «Las enseñanzas del 15-M (el léxico constitucional frente a la crisis de legitimidad)», cit., p. 6. 
que la ratio entre votos y escaños obtenidos por los partidos políticos sea tan desigual, sobrerrepresentando en el Congreso de los Diputados a los primeros en detrimento de los segundos ${ }^{16}$. Tomando los datos de las elecciones generales de 2011 como referencia, un diputado en la provincia de Madrid (donde se eligieron 36 diputados) costó 94.396 votos, en tanto que en la provincia de Soria pudo lograrse con 26.120, casi cuatro veces menos. Y mientras la media de votos por diputado de la fuerza política más votada de ámbito estatal (PP) fue de 58.000 votos y la de la segunda (PSOE) de 63.000 , la media de votos por diputado de las fuerzas minoritarias de ámbito estatal fue de 152.800 en el caso de IU y de 228.500 en el caso de UPyD. Con un 44\% de los sufragios el PP obtuvo el $53 \%$ de los escaños. IU, en cambio, con un $7 \%$ de votos obtuvo un $2 \%$ de escaños. La desigualdad en el valor del voto y en el reparto del poder era, por tanto, notable. La recomposición del sistema de partidos que se produjo en España tras las elecciones generales de 2015, con la emergencia de nuevos partidos, la desaparición de otros y la reducción de apoyos a los partidos mayoritarios, redujo los efectos desproporcionales del sistema electoral, pero no los ha eliminado, puesto que el coste de votos por diputado sigue siendo desigual y la sobrerrepresentación de los partidos más votados continúa siendo un rasgo dominante ${ }^{17}$.

La Constitución de 1978 (CE) prevé la provincia como distrito electoral, un mínimo de escaños por provincia y un número de diputados entre 300 y 400. Con esos mimbres, cabía otro sistema electoral más proporcional que el previsto en la LOREG, pero el legislador fijó en 350 el número de diputados y asignó un mínimo de dos diputados a todas las provincias, independientemente de su desigualdad demográfica. Con ello, la sobrerrepresentación en los distritos electorales pequeños es muy acusada. El sistema electoral del Congreso ha permitido la formación de gobiernos estables y conferido legitimidad, pero no es equitativo con las fuerzas minoritarias. Siempre se ha denunciado, pero han prevalecido las numerosas virtudes del sistema sobre este defecto, por lo que las iniciativas de reforma no han prosperado ${ }^{18}$. Y a ello ha contribuido el hecho de que muchos sistemas electores europeos son menos equitativos que el español. Con todo, el Consejo de Estado, en su Informe de 2009, afirmó que «el sistema electoral del Congreso de los Diputados presenta aspectos susceptibles de mejora en aras de garantizar la igualdad de electores y partidos en el proceso electoral y de revalorizar la participación de los ciudadanos en la designación de sus

16 PRESNO LINERA, M. A. (2012). « ¿Nos representan o no?», Anales de la Cátedra Francisco Suárez, 46, pp. 95-98 y GUILLÉN LÓPEZ, E. (2011). «El sistema electoral del Congreso de los Diputados: principios constitucionales y recientes propuestas de reforma», Revista Española de Derecho Constitucional, 92, pp. 213-217 y, desde una perspectiva científico-política, PENADÉS, A. y SANTAUSTE, S. (2013). «La desigualdad en el sistema electoral español y el premio a la localización del voto», Revista Española de Ciencia Política, 32, pp. 90-92.

17 PÉREZ ALBERDI, Ma . R. (2018). «Igualdad de sufragio y sistema electoral», Revista General de Derecho Constitucional, 26, pp. 11-19 (https://www.iustel.com/v2/revistas/detalle_revista.asp?numero $=26 \& i d=3$ ).

18 GARROTE DE MARCOS, $\mathrm{M}^{\mathrm{a}}$. (2020). El sistema electoral. Memoria, balance y cambio, Madrid, Marcial Pons, pp. 119-133. 
representantes. [...] Un avance en este sentido podría comportar efectos beneficiosos para el fomento de la participación política y una mayor implicación de los ciudadanos en el funcionamiento democrático de las instituciones» ${ }^{19}$. El Consejo propuso varias opciones de reforma y recopiló diferentes propuestas al respecto (desde el aumento del número total de diputados a la sustitución de la fórmula D’Hondt, pasando por la modificación de la circunscripción o del número mínimo de diputados por provincia), pero el legislador se limitó a constituir comisiones parlamentarias de estudio que no han logrado el consenso preciso para acometer la reforma de los principales elementos contenidos en la LOREG.

\subsubsection{Representatividad y funcionamiento oligárquico de los partidos}

El cuestionamiento del paradigma representativo trajo causa, asimismo, de la desafección y el rechazo que suscitan los partidos políticos, por el elitismo y el clientelismo que caracteriza su funcionamiento, por la profesionalización de sus dirigentes, por sus prácticas trapaceras y su degeneración faccional ${ }^{20}$.

La participación política representativa discurre fundamentalmente a través de los partidos políticos, que son piezas insustituibles de la democracia de masas. Los partidos son organizaciones surgidas al amparo del derecho de asociación, pero su vida interna es una cuestión que afecta al funcionamiento democrático del Estado, puesto que en el llamado Estado de partidos son los dirigentes y militantes de los partidos los que ocupan las instituciones, los que las actualizan y quienes conforman la voluntad popular. De ahí la necesidad de disciplinar la vida interna de los partidos y la exigencia de que su organización y su funcionamiento resulten plenamente conformes a los principios democráticos ${ }^{21}$. Las constituciones y leyes nacionales así suelen exigirlo, pero estamos ante mandatos deficientemente desarrollados por el legislador, incumplidos por los partidos políticos y carentes de operatividad. Así las cosas, los partidos políticos se autorregulan, limitando más bien poco el poder de la cúpula dirigente que tiende a reproducir una vez elegida las tendencias oligárquicas que fueron descritas brillantemente por Michels ${ }^{22}$.

19 VV.AA. (2009). El informe del Consejo de Estado sobre la reforma electoral, Madrid, CEPC-Consejo de Estado, pp. 157-160.

20 GUILLÉN LÓPEZ, E. (2014). «Las enseñanzas del 15-M (el léxico constitucional frente a la crisis de legitimidad)», cit., pp. 17-24. Sobre los partidos convertidos en problema para la democracia, BLANCO VALDÉS, R. L. (2015). «La caída de los dioses: de los problemas de los partidos a los partidos como problema», Teoría y Realidad Constitucional, 35, pp. 161-182. Y sobre su crisis como desencadenante de la crisis de la representación en España, GARCÍA GUITIÁN, E. (2016). «El sistema de representación política y social: aportaciones al diagnóstico sobre su crisis actual», en GUTIÉRREZ GUTIÉRREZ, I. (ed.). Decidir por mayoría, Madrid, Marcial Pons, pp. 36-40.

21 STC 56/1995, de 6 de marzo, fundamento jurídico 3.

22 «Toda organización de partido implica una poderosa oligarquía que reposa sobre pies democráticos. En todas hay electores y elegidos, pero también en todas hay un poder casi ilimitado de los dirigentes electos sobre las masas electoras. La estructura oligárquica del edificio asfixia, por tanto, su 
La Ley Orgánica 6/2002, de 27 de junio, de Partidos Políticos (LOPP) no regula la periodicidad de los congresos, la convocatoria de congresos extraordinarios ni el derecho de voto individual de los delegados; no garantiza los derechos de las minorías ni la expresión del pluralismo interno, ni disciplina el proceso de designación y elección de candidatos electorales, que constituye el nudo gordiano de la democracia representativa pues quien controla este proceso domina el sistema político. Dejados a su libre arbitrio, los partidos convocan sus congresos y reúnen a sus órganos de dirección a conveniencia del líder. Cuando lo hacen, son aclamatorios y ratificadores de decisiones ya adoptadas. Y los cargos internos y los candidatos electorales han venido siendo, en la mayoría de los partidos, cooptados por la cúpula o promocionados por el líder.

Ante el fracaso de la autorregulación se ha propugnado la intervención del legislador a fin de reequilibrar el poder en el interior de los partidos, preservando las condiciones mínimas para el ejercicio democrático y abriendo cauces efectivos de participación. La reforma de su disciplina legal resulta inaplazable, siguiendo en algunos aspectos el modelo de la Parteiengesetz, que es la norma de referencia en el Derecho de partidos, y en otros temas, como la designación de los candidatos electorales, adoptando las experiencias comparadas más consolidadas, como la detallada regulación del proceso de designación contenida en las leyes electorales alemana y finlandesa, o las experiencias más innovadoras, como la generalización de las primarias. Así lo viene reclamando la sociedad civil hace tiempo ${ }^{23}$. Y así lo demanda la doctrina, que postula la inclusión en la LOPP de, al menos, las siguientes medidas democratizadoras de su funcionamiento interno: a) la celebración de congresos cada dos años como mínimo y, en todo caso, con fecha fija y la posibilidad de solicitar la convocatoria de congresos extraordinarios; b) la elección de los órganos ejecutivos y los delegados a congresos mediante voto secreto de los afiliados o delegados al congreso y la reunión preceptiva de los denominados parlamentos internos de los partidos (Junta Directiva Nacional PP, Comité Federal PSOE, etc.) y votación secreta sobre la gestión de la ejecutiva; c) la regulación de un estatuto mínimo de las minorías dentro del partido que permita el reconocimiento de corrientes organizadas como expresión de la pluralidad interna; y d) la selección mediante elecciones internas del líder del partido y la designación mediante elecciones primarias de los candidatos a los cargos públicos representativos ${ }^{24}$.

base democrática». MICHELS, R. (1983). Los partidos políticos: un estudio sociológico de las tendencias oligárquicas de la democracia moderna, tomo 2, Buenos Aires, Amorrortu Editores, p. 189.

23 Entre las iniciativas de la sociedad civil destaca el Manifiesto por una nueva Ley de partidos impulsado por 100 intelectuales y profesionales presentado el 28 de mayo de 2013 en Madrid (disponible en http://www.eldiario.es/politica/Manifiesto-nueva-ley-partidos_0_137186391.html) y la propuesta articulada de reforma de la Ley de partidos políticos elaborada por la asociación «+ Democracia» (disponible en http://www.mas-democra-cia.org/ley_de_partidos).

24 Por todos, NAVARRO MÉNDEZ, J. I. (2009). «Siete preguntas sobre el alcance de la exigencia constitucional de democracia interna en los partidos políticos», en PAU Y VALL, F. (coord.), Parlamento y partidos políticos, Madrid, Tecnos, pp. 241-256; VÍRGALA FORURIA, E. (2015). «La regula- 
Ésta última es la propuesta más innovadora. El sistema de primarias no es el único modelo de elección democrática de candidaturas, pero es el que tiene capacidad para ofrecer mayor transparencia e igualdad de oportunidades en el proceso de designación. En las primarias pueden votar los afiliados al partido (en cuyo caso son primarias cerradas) o los afiliados y los simpatizantes que se inscriban en un censo (primarias abiertas, siguiendo el modelo de EE.UU y, recientemente, de un buen número de países latinoamericanos, que también las han regulado por ley). En Francia, Portugal y Grecia los dos principales partidos vienen celebrando primarias cerradas para elegir a sus candidatos. Y, recientemente, el Partit Socialiste Français y el Partito Demócratico italiano eligieron a sus candidatos electorales, e incluso a su secretario general en el caso del segundo, mediante primarias abiertas en las que se produjo una elevada participación ciudadana. En España, el PSOE adoptó las primarias cerradas en su $34^{\circ}$ Congreso y, tras su utilización en 1998 para designar candidato a las siguientes elecciones generales, que se saldó con la dimisión del elegido antes de los comicios, han tenido una aplicación desigual en ámbitos autonómicos y municipales. En los últimos congresos, el PSOE ha apostado por las primarias semiabiertas para designar al candidato a la Presidencia del Gobierno, pudiéndose elegir por este mismo sistema los candidatos a presidentes de las CCAA y a alcaldes de las principales ciudades. Y también ha procedido a la elección mediante elecciones internas de su secretario general. La misma decisión han adoptado el resto de los partidos políticos españoles para designar a sus respectivos líderes, así como para elegir, mediante primarias cerradas o semiabiertas, a numerosos candidatos a cargos públicos representativos. El balance no ha sido, sin embargo, precisamente positivo debido a la escasa participación, las interferencias de los aparatos y las débiles garantías de los procedimientos.

Las elecciones internas y las primarias de partido plantean no pocos problemas (división intrapartidista, posible bicefalia, debilidad de los partidos frente al hiperliderazgo, democracia de audiencia, incompatibilidad de la figura del candidato con el sistema parlamentario y con distritos plurinominales, cansancio ciudadano por la reiterada llamada al voto, etc.), pero, reguladas con los debidos contrapesos, pueden dinamizar la vida interna de los partidos, movilizar a sus afiliados y simpatizantes y romper las tendencias oligárquicas ${ }^{25}$. Estas elecciones facilitan la aparición de nuevos líderes, dotan de mayor legitimidad social a los candidatos elegidos y les otorgan autonomía respecto al aparato del partido. Y en un contexto de descrédito social de los partidos políticos, podrían servir para recobrar la confianza ciudadana. La democratización de

ción jurídica de la democracia interna en los partidos políticos y sus problemas en España», Teoría y Realidad Constitucional, 35, pp. 230-269, y GARRIDO LÓPEZ, C. (2017). «El dilema de la democracia en el interior de los partidos», Teoría y realidad constitucional, 40, pp. 338-344.

25 PAJARES MONTOLÍO, E. (2016). «Selección de candidatos y mejora del sistema electoral: consideraciones sobre las elecciones primarias», en CASCAJO CASTRO, J. L. y MARTÍN DE LA VEGA, A. (coords.), Participación, representación y democracia, Valencia, Tirant lo Blanch, pp. 175-186 y, más extensamente, sobre los tipos de primarias, sus virtudes y debilidades, PÉREZ-MONEO AGAPITO, M. (2012). La selección de candidatos electorales en los partidos, Madrid, CEPC, pp. 259-308.

(C) UNED. Revista de Derecho Politico

N. ${ }^{\circ} 112$, septiembre-diciembre 2021, págs. 139-173 
los procesos de designación de los dirigentes y de los candidatos electorales debiera ser posible. Pero ha de contar con mayores garantías que las previstas por los propios partidos y establecerse una relación coherente entre las estructuras representativas internas y la elección directa de dirigentes y candidatos; entre el liderazgo emanado de las urnas y sus posibles contrapesos orgánicos. Y para ello, posiblemente no baste la autonormación de los partidos. Deberá implicarse el legislador ${ }^{26}$.

\subsection{La cicatera regulación de las formas de democracia directa y participativa en el régimen constitucional español}

Tras la crisis de la representación y expresiones tales como «le llaman democracia y no lo es» que proferían los indignados se hallaba, asimismo, el limitado papel otorgado en nuestro país a las diversas formas de democracia directa y participativa. Y más concretamente, a la cicatera regulación y al bloqueo que, en la práctica, encuentran las formas de participación popular en los procesos de adopción de decisiones colectivas a través de comparecencias y audiencias ciudadanas en los parlamentos, a través de las iniciativas legislativas populares o mediante referéndums y consultas populares.

En los Estados democráticos modernos la participación política discurre por cauces representativos, pero ello no excluye la existencia de otros procedimientos participativos que permitan la manifestación directa de la voluntad de los ciudadanos. Al contrario, dichos procedimientos son complementarios de la democracia representativa y pueden operar como estímulo y contrapeso de la representación. En las últimas décadas, la mayoría de las constituciones han asumido semánticamente ambas vías de participación - representativa y directa-, pero regulaban con reservas las formas directas y semidirectas de expresión de la voluntad popular. Y los reglamentos parlamentarios nacionales no preveían ni mencionaban las nuevas formas de participación surgidas en algunos países, como la deliberación ciudadana en el proceso legislativo alentada y mantenida electrónicamente por el Parlamento, las audiencias y las comparecencias ciudadanas en el procedimiento de elaboración de la ley, ni las enmiendas de iniciativa ciudadana o, en el ámbito del control parlamentario del Gobierno, las preguntas de iniciativa ciudadana.

En los últimos años se está postulando, sin embargo, una constitucionalización más generosa y abierta del derecho fundamental de participación política que incluya el derecho de deliberación ciudadana en el proceso legislativo y haga mención expresa a varias formas de participación ciudadana en el procedimiento de elaboración de la

26 Con propuestas en este sentido, PAJARES MONTOLÍO, E. (2016). «Sobre la regulación de las elecciones primarias», en GARRIDO LÓPEZ, C. y SÁENZ ROYO, E. (coords.). La reforma del Estado de partidos, Madrid, Marcial Pons, pp. 71-85; BIGLINO CAMPOS, P. (2015). «Intervención del legislador y selección de candidatos por los partidos políticos: una perspectiva comparada», Teoría y realidad constitucional, 35, pp. 214-222, y GARRIDO LÓPEZ, C. (2017). «El dilema de la democracia en el interior de los partidos», cit., pp. 329-334 y 342-345. 
Ley y en el control parlamentario de la acción del Gobierno. El derecho de deliberación sería desarrollado legislativamente e implementado electrónicamente por el propio Parlamento a fin de permitir la deliberación entre los ciudadanos y entre estos y sus representantes en el proceso de discusión y elaboración de la ley. Las formas presenciales de participación política que deberían regularse, ya articuladas en algunos países de nuestro entorno, incorporadas por algunas CCAA y reguladas en sus reglamentos parlamentarios, son las comparecencias de grupos sociales ante las comisiones legislativas correspondientes, las audiencias ciudadanas, las enmiendas ciudadanas a los proyectos y proposiciones de Ley y la defensa en el debate de toma en consideración de las iniciativas legislativas populares por sus promotores. En el caso de las audiencias y comparecencias se postula — como ha señalado Presno Linera- que las minorías puedan proponerlas sin necesidad de acuerdo, y por tanto de capacidad de bloqueo, de la mayoría, como ya ocurre en el Principado de Asturias. Y en su regulación reglamentaria debería introducirse la obligación de motivación, argumentándose las razones de admisión o no de las propuestas sugeridas durante las comparecencias o audiencias $^{27}$. En el ámbito del control parlamentario a la acción de gobierno, pueden regularse, por su parte, las preguntas a iniciativa ciudadana previstas en algunos ordenamientos europeos y también en algunos reglamentos autonómicos a partir de su incorporación en 1995 en el artículo 165 del Reglamento del Parlamento andaluz, a la que siguieron otras como el artículo 172 Reglamento del Parlamento canario o el artículo 178 del murciano. Estas preguntas deben ser asumidas por un parlamentario o un grupo, quienes habrán de formularlas sin poder alterar su contenido.

La doctrina ha considerado igualmente necesario proceder a una nueva regulación constitucional de la iniciativa legislativa popular y del referéndum, figuras a través de las cuales se materializa, como el Tribunal Constitucional ha subrayado, el derecho de participación política directa de los ciudadanos reconocido en el artículo 23.1 CE ${ }^{28}$.

27 PRESNO LINERA, M. A. (2016). «La democracia participativa como instrumento de impulso, deliberación y control», en CASCAJO CASTRO, J. L. y MARTÍN DE LA VEGA, A. (coords.), Participación, representación y democracia, cit., pp. 222-228. Sobre estas formas participativas, MARTÍNEZ-PUJALTE, I. (2010). «Algunas notas sobre la participación ciudadana en el procedimiento de elaboración de las leyes», Corts. Anuario de Derecho Parlamentario, 23, pp. 261-269; CEBRIÁN ZAZURCA, E. (2017). «Las Cortes de Aragón como parlamento abierto: los mecanismos de participación ciudadana en los procedimientos parlamentarios», Estudios de Deusto, vol. 65/2, pp. 15-38, y EXPÓSITO GÓMEZ, E. (2018). «Participación ciudadana en el procedimiento de elaboración de las leyes», en VV.AA., Libro blanco sobre la calidad democrática en España, Madrid, Marcial Pons-Fundación Giménez Abad, pp. 245-256.

28 Según la STC 119/1995, de 22 de agosto (fundamento jurídico 3) las instituciones a través de las cuales se materializa dicho derecho fundamental son la iniciativa legislativa popular y el referéndum. Parte de la doctrina considera, sin embargo, en la línea propuesta por A. PIZZORUSSO [ «Democrazia rappresentativa e democrazia partecipativa», en VV.AA. (1973), Studi in memoria di Carlo Esposito, vol. III, Padua, Cedam, pp. 1473 ss.], que lo que el artículo 23.1 CE denomina participación directa, en contraposición con la participación a través de representantes, incluye dos formas de participación: la democracia directa stricto sensu y la democracia participativa, que se distinguen en función de quién tiene la última palabra sobre la cuestión a decidir: los electores o las instituciones de gobierno. En la 
En el anteproyecto de Constitución elaborado por la Ponencia en 1977 la regulación de la participación ciudadana era generosa. La iniciativa popular estaba prevista para proponer leyes sin exclusión de las materias propias de Ley orgánica y para impulsar una reforma constitucional. Podían ser objeto de referéndum la aprobación de leyes votadas por las Cortes y no sancionadas, la derogación de leyes en vigor y las decisiones políticas de trascendencia. Y la iniciativa de su convocatoria se otorgaba al Gobierno, a cualquiera de las Cámaras, a tres asambleas autonómicas y, en el caso del referéndum derogatorio, a un número acreditado de electores. En la tramitación parlamentaria posterior desaparecieron la mayoría de estas previsiones y el alcance de la participación política directa se redujo sensiblemente. Los constituyentes exageraron los peligros de estas formas de participación, se cuestionó su legitimidad y funcionalidad democráticas y se minusvaloró su rendimiento en el derecho comparado. En el recelo del constituyente pesó, asimismo, el uso plebiscitario que del referéndum hizo el régimen franquista en 1947 y 1966. Y, junto a estos factores, también se hizo presente una específica concepción del parlamentarismo patrocinada por los grupos mayoritarios: un parlamentarismo —en palabras de Garrorena Morales — «celoso a la hora de preservar la primacía institucional de Parlamento y, a su través, la de una clase política muy refractaria a cualquier recorte en su recién estrenada posición» ${ }^{29}$. A este respecto, resultan reveladores los debates en la Comisión de Asuntos Constitucionales y en el Pleno del Congreso de los Diputados protagonizados por Manuel Fraga (AP), partidario de una regulación más generosa de la democracia directa, y por Pérez Llorca (UCD) y Peces-Barba (PSOE), partidarios de su limitación en el texto constitucional $^{30}$, en los que se evidenció, como sintetizó Manuel Ramírez, que en UCD «estaba presente el temor a manifestaciones populares de participación que pudieran resultar incontroladas. En los grupos de izquierda pesaba el recuerdo de largos años de prohibición de los partidos y, en relación con el referéndum, pesaba una larga historia de manejos y corruptelas cesaristas. Y todos quisieron desquitarse

democracia directa son los propios ciudadanos quienes adoptan la decisión, pudiendo incluirse aquí el referéndum y las consultas populares. En la democracia participativa, en cambio, los ciudadanos participan en alguna fase del proceso que culmina con la decisión, pero cuya adopción final corresponde a las autoridades o instituciones competentes para ello. En esta forma de participación se incluirían la iniciativa popular para la aprobación de una Ley o resolución administrativa, las audiencias ciudadanas y la información pública en el seno de los diferentes procedimientos de aprobación de decisiones colectivas. Asumen esta distinción, entre otros, BIGLINO CAMPOS, P. (1987). «La iniciativa legislativa popular en el ordenamiento jurídico estatal», Revista española de Derecho constitucional, 19, pp. 88-92; CASTELLÀ ANDREU, J. Ma . (2013). «Democracia participativa en las instituciones representativas: apertura del Parlamento a la Sociedad», Cuadernos Manuel Giménez Abad, 5, pp. 205-206, y PRESNO LINERA, M. A. (2016). «La democracia participativa como instrumento de impulso, deliberación y control», cit., pp. 204-205.

29 GARRORENA MORALES, A. (1984). El Estado español como Estado social y democrático de Derecho, Madrid, Tecnos, p. 146.

30 Diario de Sesiones del Congreso de los Diputados (DSCD), núm. 81, Comisión de Asuntos Constitucionales y Libertades Públicas, sesión de 6 de junio de 1978, pp. 2941-2944, y DSCD, núm. 109, sesión plenaria de 13 de junio de 1978, pp. 4208-4213. 
con una opción que aseguraba la primacía de los partidos a la hora de vertebrar los cauces de la participación política. Todo o casi todo habría de pasar por los partidos. Así se quiso y así ha sido» ${ }^{31}$.

Tras el franquismo, era necesario consolidar las instituciones representativas, fortalecer los partidos políticos y lograr estabilidad para el nuevo sistema político, pero no a costa del menosprecio de los institutos de democracia directa o semidirecta, cuyo desarrollo quedó condicionado de diversos modos: a) sometiendo dichos institutos de participación ciudadana a exigencias superiores a las previstas en otros ordenamientos constitucionales comparados; b) excluyendo alguna de sus modalidades, como la iniciativa popular de reforma constitucional y los referéndums legislativos de ratificación y los abrogatorios de leyes, y; c) sometiéndolos a la tutela de los representantes, que autorizan su convocatoria (en el caso del referéndum consultivo) o dominan su toma en consideración (en el caso de la iniciativa legislativa popular). La peripecia de la transición política pudo justificar estas decisiones constitucionales. Superada la etapa de consolidación de la democracia representativa, no había, sin embargo, razones sólidas para no impulsar una mayor participación de los ciudadanos en el proceso de adopción de decisiones colectivas, de forma que, manteniendo la unidad de acción estatal, que es la función esencial de la representación política, no se menoscabe la fuerza legitimadora que la implicación popular proporciona al proceso político. Así lo sostuvo pronto alguna doctrina ${ }^{32}$. Y así se ha venido reclamando, a fin de articular formas efectivas de democracia de contrapeso e integrar a quienes se sienten excluidos del sistema representativo.

\section{LAS PROPUESTAS DE IMPULSO DE LAS FORMAS DE DEMOCRACIA DIRECTA Y PARTICIPATIVA EN LA X LEGISLATURA DE LAS CORTES GENERALES}

Evidenciadas, en el contexto de la crisis económica, las carencias y limitaciones de las instituciones representativas, resurgió con fuerza el debate en torno a la conveniencia de impulsar una mayor implicación ciudadana en los asuntos públicos, potenciando los mecanismos de participación en los procedimientos parlamentarios, flexibilizando los requisitos de la iniciativa popular e incorporando nuevas modalidades de referéndum, como los referéndums propositivos de normas, los legislativos de ratificación o los abrogatorios de leyes en vigor. Debilitado el idem sentire entre representantes y representados, interrumpida la suspensión voluntaria de la incredulidad

31 RAMÍREZ JIMÉNEZ, M. (1985). La participación política, Madrid, Tecnos, pp. 55-56.

32 RAMIREZ JIMÉNEZ, M. (1992). «El reforzamiento de la participación política», Revista de Derecho Político, 36, pp. 31-45, y AGUIAR DE LUQUE, L. (2000). «Democracia directa e instituciones de democracia directa en el ordenamiento constitucional español», en TRUJILLO, G., LÓPEZ GUERRA, L. Ma. y GÓNZÁLEZ-TREVIJANO, P. J. (coords.), La experiencia constitucional (1978-2000), Madrid, CEPC, pp. 96-97

(C) UNED. Revista de Derecho Politico

N. ${ }^{\circ} 112$, septiembre-diciembre 2021, págs. 139-173 
en que se asienta el dogma de la representación política ${ }^{33}$, muchos ciudadanos reclamaron nuevas vías de participación que les permitieran incidir efectivamente en el proceso de formación de la voluntad general. Y así lo hicieron llegar a las instituciones a través de peticiones colectivas, asociaciones y partidos, desde que la indignación que cristalizó el 15 de mayo de 2011 sirviera de catalizador de diversas demandas de regeneración democrática. Recogiendo estas demandas, se han sucedido varias propuestas tanto en el ámbito académico ${ }^{34}$, como en sede parlamentaria, donde se han registrado dos proposiciones de reforma constitucional de los artículos 87, 92 y 166 de la CE.

La primera de ellas, presentada por el Grupo Parlamentario Mixto y el Grupo de IU, ICV-EUiA, CHA: La Izquierda Plural el 13 de mayo de 2013, pretendía eliminar los límites materiales de la iniciativa legislativa popular, garantizar su defensa en las Cortes Generales por parte de sus promotores, exigir la celebración de un referéndum para ratificar toda reforma constitucional y ampliar los supuestos para la convocatoria de referendos consultivos, flexibilizando sus requisitos y reconociendo la facultad de las CCAA y los entes locales para convocarlos en su ámbito territorial y en asuntos de su competencia. La proposición fue admitida a trámite por la Mesa del Congreso el 21 de mayo de 2013, pero caducó sin tomarse en consideración por el Pleno ${ }^{35}$. Con mayor calidad técnica, la Junta General del Principado de Asturias presentó el 16 de octubre de 2014 una nueva proposición de reforma constitucional que afectaba a los artículos 87, 92 y $166 \mathrm{CE}$, en la que se pretendía la eliminación de las materias propias de Ley orgánica y la reforma constitucional de entre los límites materiales de la iniciativa legislativa popular, la incorporación de la figura del referéndum legislativo abrogatorio en parecidos términos a los del artículo 75 de la Constitución italiana y

33 Sobre la idea de la suspensión voluntaria de la incredulidad como fundamento del gobierno representativo, MORGAN, E. S. (2006). La invención del pueblo. El surgimiento de la soberanía popular en Inglaterra y los Estados Unidos, Buenos Aires, Siglo XXI, pp. 13-14.

34 En el ámbito académico destacan CASTELLÀ ANDREU, J. Mª . (2016), «El referéndum en la Constitución: ¡es necesario un replanteamiento de la institución?», en CASCAJO CASTRO, J. L. y MARTÍN DE LA VEGA. A. (coords.), Participación, representación y democracia, cit., pp. 235-266; PRESNO LINERA, M. Á. (2014). «La democracia directa y la falacia de sus riesgos», en GUTIÉRREZ GUTIÉRREZ, I. (coord.), La democracia indignada. Tensiones entre la voluntad popular y representación política, cit., pp. 61-92; REQUEJO RODRÍGUEZ, P. (2014). «El referéndum consultivo en España: reflexiones críticas y algunas propuestas de futuro», Estudios de Deusto, 62/1, pp. 261-284; VÍRGALA FORURIA, E. (2015). «Representación, parlamentarismo y democracia participativa», en GARCÍA HERRERA, M. A., ASENSI SABATER, J. y BALAGUER CALLEJÓN, F. (coords.), Constitucionalismo crítico. Liber amicorum Carlos de Cabo Martín, Valencia, Tirant lo Blanch, pp. 10551083; DÍAZ REVORIO, F. J. (2018). «Democracia, representación y participación ciudadana. A la búsqueda de un equilibrio que la Constitución no logró», Revista de Derecho Político, 101, pp. 239-270; MORALES ARROYO, J. M. a (2018). «El alcance y los límites de los instrumentos constitucionales de participación directa», Revista General de Derecho Constitucional, 26, (https://www.iustel.com/v2/ revistas/detalle_revista.asp?id=3\&numero=26) y SÁENZ ROYO, E. (2018). El referéndum en España, Madrid, Marcial Pons, pp. 150-160.

35 BOCG, Congreso de los Diputados, Serie B, núm. 122-1, 24 de mayo de 2013, pp. 1-4. 
la ampliación de la iniciativa para convocar referéndums a 500.000 electores $^{36}$. La proposición de reforma fue admitida a trámite el 21 de octubre de 2014. Disueltas las Cortes Generales, fue trasladada al Congreso de la XI Legislatura y, tras las nuevas disoluciones anticipadas, al de las XII, XIII y XIV Legislaturas, sin que todavía haya sido tomada en consideración ${ }^{37}$.

Más allá de sus diferencias, todas estas proposiciones y los posicionamientos doctrinales partían de las mismas premisas: a) que la pretendida incompatibilidad entre las formas representativas e inmediatas de participación política era falsa, y b) que regenerar la democracia exigía hacerla también más participativa, impulsando a tal efecto la utilización de los principales institutos a través de los cuales se materializa el derecho de participación política de los ciudadanos. Sintetizando su contenido, estas propuestas postulaban, en primer lugar, impulsar el ejercicio de la iniciativa legislativa popular reduciendo el número de firmas exigidas, ampliando las materias sobre las que pueden versar y dando voz a sus promotores en el Parlamento; y, en el ámbito del referéndum, pretendían introducir nuevas modalidades, como el referéndum propositivo de normas, el legislativo de ratificación y el abrogatorio de leyes en vigor, ampliar los sujetos legitimados para instar su convocatoria y reforzar sus garantías normativas.

\section{LA INICIATIVA LEGISLATIVA POPULAR COMO INSTRUMENTO DE DEMOCRACIA PARTICIPATIVA}

La iniciativa legislativa popular consiste en la atribución de la facultad de iniciar el procedimiento de elaboración de una Ley a una determinada fracción del cuerpo electoral, que propone un texto al Parlamento para que este, en su caso, decida

36 BOCG, Congreso de los Diputados, Serie B, núm, 194-1, 24 de octubre de 2014, pp. 1-3. Dicha proposición fue aprobada en la Asamblea autonómica por los grupos parlamentarios socialista, mixto y de Izquierda Unida y traía causa de la propuesta «Por una democracia directa» presentada al amparo del derecho de petición reconocido en el artículo 29 CE por varias decenas de ciudadanos ante varios parlamentos autonómicos, y que en Asturias el Grupo Parlamentario de Izquierda Unida había hecho propia y formalizado parlamentariamente a través de una proposición de las del artículo 166 CE. Un análisis de la gestación y del contenido de la proposición, que en su inicio era más ambiciosa, en PRESNO LINERA, M. A. (2017). «Propuesta de reforma de la Constitución para promover la participación ciudadana», en https://presnolinera.wordpress.com/2014/02/17/propuesta-de-reforma-de-la-constitucion-para-promover-la-participacion-ciudadana/ (consultado el 10 de octubre de 2020). Más ampliamente, GARRIDO LÓPEZ, C. (2019), «La iniciativa popular de referéndum», Teoría y realidad constitucional, 43, pp. 337-341, y LÓPEZ RUBIO, D. (2019), «Radiografía de una propuesta olvidada: la proposición de reforma constitucional de la Junta General asturiana sobre democracia semidirecta», Estudios de Deusto, vol. 67, 2, pp. 263-295.

37 La proposición de reforma ha sido admitida nuevamente a trámite por la Mesa del Congreso el 13 de diciembre de 2019 y publicada en el BOCG, Congreso de los Diputados, Serie B, núm. 1-1, 20 de diciembre de 2019. Desde el 29 de febrero de 2020 se halla pendiente de toma en consideración por el Pleno.

(C) UNED. Revista de Derecho Politico

N. ${ }^{\circ} 112$, septiembre-diciembre 2021, págs. 139-173 
debatirlo, modificarlo y, finalmente, votarlo. Este instrumento de participación puede mejorar la calidad del procedimiento legislativo porque amplía los sujetos legitimados para incoarlo, enriquece el debate con nuevos temas que no figuran en la agenda y fortalece su legitimación. La iniciativa legislativa popular puede servir, como subrayó Requejo Rodríguez, para que lleguen al Parlamento preocupaciones e intereses ignorados por provenir de colectivos que no están o no se sienten representados. Y, debidamente regulada, puede actuar como un medio de participar en el proceso de formación de la voluntad general conservando las Cámaras la plena capacidad decisoria sobre la oportunidad y el contenido de la iniciativa ${ }^{38}$.

A diferencia de la iniciativa popular de referéndum de origen suizo, en la que una fracción del cuerpo electoral solicita la celebración de un referéndum sobre una reforma constitucional o sobre una texto legislativo propuesto o existente para su aprobación o rechazo, la iniciativa legislativa popular se dirige al Parlamento, que conserva en todo momento la libertad de rechazarla o bien admitirla y transformarla en ley. En rigor, ambas modalidades no son excluyentes, puesto que en algunos Estados norteamericanos, como Massachusetts, Michigan, Nevada o Maine, en la totalidad de los Länder alemanes y en varias regiones italianas, existe una iniciativa popular mixta o reforzada que se dirige en primer término a la asamblea para que la tramite y, en su caso, la apruebe en un plazo determinado, pero que, en el supuesto de no hacerlo o de introducir enmiendas que la desnaturalicen, la propuesta se somete a votación popular $^{39}$. La iniciativa legislativa popular no responde, sin embargo, a este modelo que puede acabar en referéndum. La iniciativa legislativa popular reserva el control de la propuesta en todo momento al Parlamento. Y tras su incorporación en la Constitución austriaca de 1920, de donde pasó a la Constitución española de 1931 y a la Constitución italiana de 1947, fue la fórmula de iniciativa popular más extendida en el derecho comparado.

\subsection{El fracaso y la necesaria revisión de la iniciativa legislativa popular}

El artículo 87.3 CE recuperó la institución en nuestro ordenamiento y reconoció la iniciativa popular para presentar proposiciones de Ley en las Cortes Generales, remitiendo su desarrollo a una posterior Ley orgánica e indicando que «en todo caso

38 REQUEJO RODRÍGUEZ, P. (2014). «Iniciativa legislativa popular y protección de minorías», comunicación presentada en el XII Congreso de la Asociación de Constitucionalistas de España, Salamanca, 3 y 4 de abril de 2014, p. 2 (se maneja copia del original).

39 Sobre la iniciativa ciudadana mixta o reforzada por su vinculación con el referéndum, véanse, respectivamente, CRONIN, T. E. (1989). Direct Democracy. The Politics of Initiative, Referendum, and Recall, Cambridge, Harvad University Press, p. 192-194; JÜRGENS, G. (1993). Direkte Demokratie in den Bundesländern, Gemeinsamkeiten-Unterschiede-Erfabrungen, Vorbildfunktion für den Bund?, Stuttgart, pp. 276-279 y RODEAN, N. (2020). «Los referéndums y la iniciativa reforzada en los nuevos estatutos regionales italianos», en SÁENZ ROYO, E. y GARRIDO LÓPEZ, C. (dirs.), El referéndum y su iniciativa en el derecho comparado, Valencia, Tirant lo Blanch, pp. 259-269. 
se exigirán no menos de 500.000 firmas acreditadas» de electores para impulsarla. Se excluyeron de la iniciativa legislativa popular las materias propias de Ley orgánica, las tributarias y las de carácter internacional, así como «lo relativo a la prerrogativa de gracia». Y tampoco se admitió para instar la reforma de la Constitución, puesto que el artículo $166 \mathrm{CE}$ remite únicamente a los apartados 1 y 2 del artículo $87 \mathrm{CE}$.

La Ley Orgánica 3/1984, de 26 de marzo, reguladora de la iniciativa legislativa popular (LOILP), introdujo más dificultades, como el reducido plazo de recogida de firmas o las numerosas causas formales de inadmisión que pueden ser apreciadas por la Mesa del Congreso. Y la interpretación realizada sobre las materias excluidas y las causas de inadmisión tanto por la Mesa como por el Tribunal Constitucional, que declaró inadmisibles varios recursos de amparo ${ }^{40}$, limitó aún más su ejercicio. La reforma de la LOILP realizada en 2006 amplió el plazo para la recogida de firmas de seis a nueve meses, prorrogables por otros tres, admitió la validez de la firma electrónica y suprimió algunas causas de inadmisión de carácter procedimental ${ }^{41}$. Esta mejora propició un incremento significativo de las iniciativas legislativas populares, pero ese renovado interés ciudadano no fue acompañado de un cambio de actitud de los grupos parlamentarios, quienes se han mantenido inflexibles a la hora de desecharlas, posiblemente por plantear asuntos que no deseaban incluir en la agenda política.

Un análisis empírico del rendimiento de la institución ofrece datos decepcionantes. Desde 1983 hasta octubre de 2020 se han puesto en marcha 121 iniciativas legislativas populares: 45 de ellas caducaron antes de lograr reunir en plazo el número de firmas exigido, 46 fueron inadmitidas a trámite por la Mesa, bien por abordar cuestiones excluidas del ámbito de la iniciativa legislativa popular o por causas procedimentales, 6 iniciativas fueron retiradas o decayeron y varias siguen pendientes. Sólo 12 iniciativas lograron en todo este tiempo ser admitidas a trámite ${ }^{42}$. De éstas, la mayoría fueron rechazadas en la toma en consideración por carecer del apoyo partidista necesario. Hasta 2013 sólo una iniciativa legislativa popular llegó a convertirse en Ley (la Ley 8/1999, de 6 de abril, de reforma de la Ley 49/1960, de 21 de julio, de Propiedad Horizontal), pero subsumida en otra iniciativa legislativa de origen parlamentario que la desnaturalizó. Sorprendentemente, en 2013 fueron tomadas en

40 AATC 26/1985, de 16 de enero, y 592/1985, de 18 de septiembre. Sobre la regulación constitucional de la iniciativa legislativa popular y su primer desarrollo legal, CONTRERAS CASADO, M. (1986). «Iniciativa legislativa popular y Estado democrático de derecho (una aproximación a su regulación jurídica en España)», Revista de las Cortes Generales, 8, pp. 67-94; BIGLINO CAMPOS, P. (1987). «La iniciativa legislativa popular en el ordenamiento jurídico estatal», cit., p. 75-130, y ASTARLOA VILLENA, F. (2003). «La iniciativa legislativa popular en España», Teoría y realidad constitucional, 10-11, pp. 273-321.

${ }_{41}$ Un análisis de las reformas de 2006 en ARANDA ÁLVAREZ, E. (2006). «La nueva Ley de iniciativa legislativa popular», Revista Española de Derecho Constitucional, 78, pp. 187-218; MARCO MARCO, J. J. (2009). «La iniciativa legislativa legislativa popular en España (o el mito de Sísifo)», Revista General de Derecho Constitucional, 8, pp. 2-33.

42 Las iniciativas legislativas populares activadas pueden verse en http://www.juntaelectoralcentral.es/cs/jec/ilp/legislaturas (consultada el 15 de octubre de 2020). 
consideración el mismo día dos iniciativas populares: la proposición de Ley para la regulación de la tauromaquia como patrimonio cultural, que fue aprobada con modificaciones tras su tramitación parlamentaria, y la proposición de Ley de regulación de la dación en pago, paralización de los desahucios y alquiler social, que quedó subsumida en otra proposición de Ley de origen parlamentario, dando como resultado la Ley $1 / 2013$, de 14 de mayo, de medidas para reforzar la protección a los deudores hipotecarios, reestructuración de deuda y alquiler social, que no prevé la dación en pago ni la paralización de los desahucios.

Con este pobre balance no es difícil compartir la conclusión de Requejo Rodríguez, para quien «estamos ante una configuración de la iniciativa legislativa popular semejante a una especie de derecho de petición articulado, que en el plano teórico desvirtúa su naturaleza participativa, en el plano funcional no contribuye a verla como garantía de las minorías y en el plano práctico la condena al fracaso. Se impone una revisión sustancial que asegure no que la iniciativa popular llegue a imponerse, sino que al menos llegue a debatirse» ${ }^{43}$. Y en la necesidad de esa revisión coincide la práctica totalidad de la doctrina, que ha considerado esta figura «un elemento ornamental de la Constitución destinado a permanecer en el anonimato» ${ }^{44}$, «un mecanismo de participación de dimensiones mínimas, casi ridículas» y «un mero brindis al sol» ${ }^{45}$.

\subsection{La reducción del número de firmas y de las materias excluidas. La apuesta por la iniciativa popular mixta o reforzada vinculada al referéndum}

La cifra de firmas requerida en el artículo 87.3 CE para que pueda presentarse la iniciativa legislativa es extraordinariamente alta en comparación con la exigida en otros ordenamientos constitucionales. En España, con un total de 36.956.222 electores incluidos en el censo electoral de españoles residentes (CER) y en el censo de españoles residentes en el extranjero (CERA) se exigen 500.000 firmas acreditadas, en tanto que en Polonia, con 31 millones de electores, se exigen 100.000 firmas, y en Italia, con 50 millones de electores, sólo 50.000 firmas. El número de firmas requerido también es inferior en Hungría (50.000), Holanda (40.000) y Portugal (35.000). Y si tomamos en consideración la iniciativa ciudadana europea, regulada en el Reglamento (UE) 211/2011 del Parlamento Europeo y del Consejo, de 16 de febrero, para la que se precisa un millón de firmas, llegamos a idéntica conclusión, puesto que, aun siendo el doble la cifra exigida en la UE, resulta mucho más fácil de alcanzar que la prevista en España teniendo en cuenta el número potencial de

43 REQUEJO RODRÍGUEZ, P. (2014). «Iniciativa legislativa popular y protección de minorías», cit., p. 12. Y de la misma autora, (2016). «La posición de las minorías en el Estado democrático», en GUTÍÉRREZ GUTIÉRREZ, I. (ed.). Decidir por mayoría, cit., p. 113.

44 ARNALDO ALCUBILLA, E. (2008-2009). «Iniciativa legislativa popular», en Enciclopedia Jurídica La Ley, tomo 12, Madrid, La Ley, p. 6636.

45 MARCO MARCO, J. J. (2009). «La iniciativa legislativa popular en España (o el mito de Sísifo)», cit., p. 2. 
firmantes, aunque deban proceder de, al menos, siete Estados miembros y superar un número mínimo en cada uno de ellos.

Las exclusiones materiales previstas en el artículo 87.3 CE y, por remisión, en el artículo $166 \mathrm{CE}$ resultan igualmente excesivas, puesto que la iniciativa legislativa popular es una simple propuesta que, pese a su relevancia política, puede ser rechazada o modificada libremente en sede parlamentaria. Con la exclusión de las materias propias de Ley Orgánica se priva a los ciudadanos de la posibilidad de impulsar propuestas legislativas sobre cuestiones directamente relacionadas con el desarrollo constitucional, como la regulación de los derechos fundamentales y las libertades públicas, los elementos del régimen electoral general, los contenidos de los Estatutos de Autonomía y las instituciones y órganos que, por mandato constitucional, como la propia iniciativa legislativa popular y el referéndum, precisan ser implementadas mediante Ley Orgánica y que constituyen una larga lista. Quedan excluidas, por tanto, del ámbito de la iniciativa popular todas aquellas materias que, en mayor medida, podrían interesar, movilizar e implicar a los ciudadanos y a los grupos sociales en que se integran en un proceso participativo de naturaleza legislativa.

Excluyendo la iniciativa popular en la reforma constitucional se veta, asimismo, a los ciudadanos la posibilidad de impulsar y proponer cambios en la Norma Suprema. Dada la prudencia con que, a juicio de alguna doctrina, debía afrontarse la reforma de la Constitución, la iniciativa quedó reservada a las instituciones representativas ${ }^{46}$. En nuestra opinión, esta exclusión resulta difícilmente justificable. Impedir la iniciativa popular en la reforma constitucional es «una contradicción notable» con el principio de soberanía popular proclamado en el artículo $1.2 \mathrm{CE}^{47}$. Además, la participación directa de los ciudadanos en la fase final de la reforma no está asegurada en el procedimiento ordinario del artículo $167 \mathrm{CE}$ y, en cualquier caso, no es lo mismo intervenir para ratificar una decisión ya tomada por las Cortes Generales que impulsar su gestación, identificando los potenciales aspectos a reformar.

Por las razones expuestas, la doctrina propugna la revisión de los artículos 87.3 y 166 CE. En el primero, debería reducirse el número de firmas exigido, adoptándose una cifra similar a la prevista en la regulación constitucional italiana, y eliminarse las materias propias de Ley Orgánica del listado de exclusiones del artículo, donde, al igual que en el anteproyecto de Constitución, sólo quedarían excluidas las materias internacionales, a fin de respetar las facultades que las Cortes Generales tienen atribuidas en los artículos 93 a 96 CE; y también las materias tributarias, en razón del protagonismo del Parlamento en este ámbito, que está en los orígenes de la propia institución; las materias presupuestarias, cuya iniciativa el artículo 134 CE reserva al Gobierno en ejercicio de su facultad de dirección política, y lo relativo al derecho de

46 En este sentido, PÉREZ ROYO, J. (1987). La reforma de la Constitución, Madrid, Congreso de los Diputados, pp. 143-149.

47 DE VEGA, P. (1986). La reforma constitucional y la problemática del poder constituyente, Madrid, Tecnos, p. 134.

(C) UNED. Revista de Derecho Político

N. ${ }^{\circ} 112$, septiembre-diciembre 2021, págs. 139-173 
gracia, por incidir sobre una facultad gubernamental de ejercicio discrecional ${ }^{48}$. Por su parte, el artículo 166 CE debería admitir la iniciativa popular para incoar los procedimientos de reforma constitucional a una fracción del cuerpo electoral, a semejanza de lo previsto en Suiza, donde 100.000 electores pueden instar una reforma total o parcial de la Constitución (arts. 138 y 139 de la Constitución) o en Austria, cuya Constitución legitima a 200.000 electores o a la mitad de los electores en cada uno de tres Länder para presentar proposiciones de reforma constitucional (art. 41). En todos los casos, el artículo 87.3 CE debería garantizar la defensa de la iniciativa popular por la persona o personas designadas por los promotores en el debate de toma en consideración y/o durante su tramitación en la comisión parlamentaria correspondiente, según está previsto ya en varios ordenamiento jurídicos autonómicos (Andalucía, Aragón, Cataluña, Canarias, Galicia e Illes Balears ${ }^{49}$ ), así como la posibilidad de solicitar la retirada de la proposición de Ley en el caso de que, vía enmiendas, quedara manifiestamente desvirtuada (así se prevé en Cataluña y Aragón) ${ }^{50}$.

Estas reformas se consideran necesarias para poder impulsar la iniciativa legislativa popular en España, pero serán insuficientes si no van acompañadas también de un cambio de actitud de los parlamentarios que permita superar sus tradicionales recelos hacia la participación ciudadana en la elaboración de la ley ${ }^{51}$. La hostilidad y la desconfianza, acaso justificables en los momentos fundacionales del sistema democrático, deberían dar paso a la colaboración, puesto que la iniciativa popular no cuestiona la democracia representativa, sino que la complementa, dinamizándola con la introducción de nuevos temas en la agenda política. Alguna doctrina, sin embargo, considera ilusorio que dicho cambio de actitud vaya a producirse y juzga estéril cualquier reforma de la institución mientras los grupos parlamentarios mantengan el control y puedan rechazar las iniciativas sin siquiera debatirlas. "Ninguna reforma — afirma Biglino Campos_ que incidiese en [...] las materias excluidas, el procedimiento de recogida de firmas, la admisión y discusión por las asambleas, por muy

48 En este sentido, BIGLINO CAMPOS, P. (1987). «La iniciativa legislativa popular en el ordenamiento jurídico español», cit., pp. 108-109. En la doctrina más reciente, ARANDA ÁLVAREZ, E. (2017). «La iniciativa legislativa popular. Reformas para mejorar su ejercicio», en PÉREZ-MONEO AGAPITO, M. y VINTRÓ CASTELLS, J. (coords.), Participación política: deliberación y representación en las Comunidades Autónomas, Madrid, Congreso de los Diputados, pp. 192-204.

49 ARNALDO ALCUBILLA, E. (2013). «La iniciativa legislativa popular en los regímenes autonómicos», en ARNALDO ALCUBILLA, E., DELGADO-IRIBARREN, M. y SÁNCHEZ NAVARRO, A. J., Iniciativa legislativa popular, Madrid, La Ley-Univ. Rey Juan Carlos, pp. 257-396.

50 En este sentido, GARCÍA MAJADO, P. (2017). «La configuración de la iniciativa legislativa popular: resistencias y soluciones», Oñati Socio-Legal Series, vol. 7, 5, pp. 1054-1054. En contra, DURÁN ALBA, J. F. (2016) considera que esta retirada no es congruente con la naturaleza de la institución, pues supone una injerencia de quien no es titular ni de la potestad legislativa ni, formalmente de su iniciativa durante la tramitación de la misma. Cfr. «Los partidos políticos en la recogida de firmas y el debate parlamentario de la iniciativa legislativa popular», en BIGLINO CAMPOS, P. ( $\operatorname{coord}^{\mathrm{a}}$.), Partidos políticos y mediaciones de la democracia directa, Madrid, CEPC, p. 94.

51 VIDAL MARÍN, T. (2015). «Regeneración democrática e iniciativa legislativa popular», InDret. Revista para el Análisis del Derecho, núm. 2, 2015, p. 53 (http://www.indret.com/pdf/1131_es.pdf). 
profunda que fuera, lograría relanzar la figura, dado que el problema está en la propia naturaleza de la institución [...], en la que son las fuerzas políticas con representación parlamentaria quienes toman la decisión» ${ }^{52}$.

Para lograr algún cambio real, creemos, por ello, que el constituyente debería incorporar a nuestro ordenamiento la figura de la iniciativa popular propositiva o reforzada, aquella en que la propuesta normativa, de no ser tomada en consideración o resultar rechazada por el Parlamento, debe ser sometida a referéndum; en algunos lugares — como se prevé en varios Estados norteamericanos y en los Länder alemanes - junto con la contrapropuesta que el Parlamento podría formular ${ }^{53}$. Sólo con esta fórmula mixta, que priva de la última palabra al Parlamento entregándola, llegado el caso, al cuerpo electoral, la iniciativa legislativa popular dejaría de ser el instrumento de frustración ciudadana en que se ha convertido allí donde está instituida, desde España a Italia o Austria, e incluso en la UE, donde — como Suárez Antón ha subrayado- la iniciativa ciudadana europea también es cuestionada ${ }^{54}$. Y ello porque la iniciativa mixta o reforzada representa, ante la posibilidad de activar la opinión del cuerpo electoral, un estímulo cierto de la receptividad parlamentaria hacia las proposiciones legislativas ciudadanas y promueve entre los representantes y la sociedad civil una dinámica integradora y políticamente consensual ${ }^{55}$.

\section{LA FUNCIONALIDAD DEL REFERÉNDUM EN LAS DEMOCRACIAS REPRESENTATIVAS}

La democracia moderna es esencialmente representativa, pero ello no impide «que el poder de decisión y dirección representativo se pueda corregir y contrapesar democráticamente [...] mediante la decisión directa sobre ciertos asuntos por el pueblo mismo» ${ }^{56}$. Respondiendo a esta lógica integradora de ambas formas de participación política, la mayoría de los ordenamientos constitucionales han incorporado a su estructura institucional la figura del referéndum. En algunos, su regulación es muy restrictiva y su utilización resulta excepcional, como ocurre en España. En otros, en

52 BIGLINO CAMPOS, P (2016). «Conclusiones y propuestas», en BIGLINO CAMPOS, P. (coord ${ }^{\mathrm{a}}$.), Partidos políticos y mediaciones de la democracia directa, cit., p. 397.

53 SÁENZ ROYO, E. (2018). El referéndum en España, cit., pp. 155-156.

54 SUÁREZ ANTÓN, O. J. (2019). «Auge y declive de la iniciativa ciudadana europea: ¿guardar las apariencias o garantizar la participación?», Revista Española de Derecho Europeo, 69, pp. 49-83.

55 GERBER, E. R. (1996). «Legislative Response to the Threat of Popular Initiatives», American Journal of Political Science, 40 (1), pp. 99-102 (disponible en: https://doi.org/10.2307/2111696) y KRIESI, H. y TRECHSEL, A. (1996). "Switzerland: the referendum and initiative as centerpiece of the political system», en GALLAGHER, M. y ULERI, P. V. (eds.). The Referendum Experience in Europe, London: Macmillan Press, 200-202.

56 BÖCKENFÖRDE, A. W. (1993). «Democracia y representación. Crítica a la discusión actual sobre la democracia», cit., pp. 143-144.

(C) UNED. Revista de Derecho Politico

N. ${ }^{\circ} 112$, septiembre-diciembre 2021, págs. 139-173 
cambio, el uso del referéndum ha crecido exponencialmente en los últimos años y se ha generalizado en todos los niveles de gobierno.

En Irlanda, la participación directa mediante referéndum constituye un rasgo característico de su régimen político, habiéndose celebrado decenas de referendos de carácter constitucional y sobre tratados europeos desde 1937. En Alemania, la Grundgesetz sólo establece el referéndum nacional para el cambio en los límites administrativos (art. 29), pero la totalidad de los Länder prevén la celebración de referéndums legislativos y para la reforma constitucional, en ambos casos a iniciativa de un porcentaje del cuerpo electoral, habiéndose celebrado en los últimos años más de 220 referendos estatales. Durante la V República, en Francia han tenido lugar varias decenas de consultas nacionales y de ámbito regional. Y en la reforma constitucional de 2008, se ha introducido el referéndum legislativo de iniciativa compartida o concurrente, atribuida a una quinta parte de los miembros de la Asamblea Nacional avalada por, al menos, una décima parte del cuerpo electoral. En Reino Unido, donde el referéndum carecía de tradición, en los últimos años ha adquirido protagonismo para consultar sobre decisiones políticas de especial trascendencia, como la pertenencia a la Unión Europea, la reforma del sistema electoral o cuestiones territoriales, y se ha dotado de una rigurosa regulación contenida en la Political Parties, Elections and Referendums Act 2000.

Suiza e Italia merecen mención aparte por su frecuente utilización del referéndum. En Suiza, la experiencia referendataria se remonta al nacimiento de la primera constitución confederal. En las últimas décadas su uso se ha incrementado y desde 1980, concretamente, se han celebrado más de 300 referendos constitucionales y legislativos a nivel federal, a los que habría que añadir varios cientos más a nivel cantonal, la mayoría a iniciativa popular. En Italia, desde el primer referéndum abrogatorio que tuvo lugar en 1974, se han celebrado 70 referéndums nacionales, que han abarcado temas tan dispares como la investigación con embriones y fecundación asistida, la edad de jubilación, la energía nuclear, las privatizaciones del agua y los impedimentos procesales a favor de los miembros del Gobierno. El referéndum abrogatorio de leyes reviste allí una relevancia capital, pues permite a las minorías introducir en el debate público temas al margen de la voluntad de los grandes partidos. Y lo mismo cabría decir del rendimiento del referéndum en veinticuatro Estados de EEUU, en los que, además del referéndum legislativo a iniciativa de los gobiernos estatales, que está previsto en todos los Estados de la Unión, se celebran referéndums legislativos y constitucionales a iniciativa popular que determinan la agenda política e introducen reformas que no habrían prosperado de depender de los propios partidos ${ }^{57}$.

57 Una relación completa de los referendos celebrados por países, puede verse en la web http:// www.c2d.ch/inner.php?table=dd_db\&link_id=61\&parent_id=61del Centre for Research on Direct Democracy de la Universidad de Zurich (consultada el 20 de marzo de 2020). 
En ninguno de los países citados la democracia ha sucumbido a la demagogia por la práctica de la democracia directa. El incremento en el uso del referéndum no ha menoscabado ni la posición constitucional de los Parlamentos ni el poder de representación del pueblo que dichos órganos tienen asignados y que siguen detentando con la sola reserva del eventual ejercicio directo del derecho de participación a través de referéndum. Regulado con las garantías precisas, el referéndum amplía las posibilidades de participación, implica a los ciudadanos en el proceso de adopción de las decisiones colectivas y refuerza la legitimidad del sistema político. El referéndum puede ser, por ello, un instrumento eficaz de integración política. Y puede operar como acreditado complemento de la democracia representativa, posibilitando la participación popular directa en el proceso constituyente, legislativo o gubernamental de adopción de decisiones, como ocurre con los referendos de reforma constitucional, los propositivos de normas, los legislativos de ratificación y los abrogatorios de leyes en vigor.

\section{LA REGULACIÓN Y LA ESCASA PRÁCTICA DEL REFERÉNDUM EN ESPAÑA. DE NUEVO EL DEBATE SOBRE SUS RIESGOS}

La experiencia española en materia de referéndum es muy limitada. Durante la II República se celebraron tres plebiscitos de aprobación estatutaria en Cataluña (1932), País Vasco (1933) y Galicia (1936), pero el referéndum legislativo previsto en el artículo 66 de la Constitución quedó inédito. Bajo el régimen franquista se celebraron dos referendos nacionales y, a su término, tuvo lugar un tercero para ratificar la Ley para la Reforma Política, pero todos ellos se llevaron a cabo sin pluralismo político ni garantías democráticas ${ }^{58}$. La escasa práctica y el recuerdo de estos precedentes configuraron un estado de opinión constituyente poco favorable al referéndum y mayoritariamente partidario de reforzar las instituciones de la democracia representativa. Y en ese estado de opinión pesó la cautela hacia la instrumentalización de la democracia directa por grupos políticos minoritarios y el miedo a la demagogia basado en la creencia de que el referéndum en España iba a ser, parafraseando la conocida frase de Carl von Clausewitz, la continuación de la política parlamentaria y de enfrentamiento de partidos por otros medios ${ }^{59}$.

Ello explica que la «segunda ponencia» constituida de facto en la Comisión de Asuntos Constitucionales del Congreso descartara el referéndum de ratificación o suspensivo de leyes aprobadas antes de su sanción regia y el referéndum abrogatorio de leyes vigentes, ambos con pluralidad de proponentes, que los miembros de la

58 Sobre estos precedentes, AGUIAR DE LUQUE, L. (1977). Democracia directa y Estado constitucional, Madrid, Edersa, pp. 240-253 y 274-203.

59 RUIZ ROBLEDO, A. (2014). «Teoría y práctica del referéndum en el ordenamiento constitucional español», en CONTRERAS CASADO, M. y SÁENZ ROYO, E. (eds.), La participación política directa. Referéndum y consultas populares, Zaragoza, Comuniter, p. 48. 
Ponencia constitucional habían incluido en el anteproyecto de Constitución ${ }^{60}$. Y esa prevención explica, asimismo, que tras el paso del anteproyecto por la Comisión de Asuntos Constitucionales, el constituyente sólo asumiera tres tipos de referendos: el referéndum preceptivo previsto en caso de reforma constitucional por el procedimiento agravado de revisión (art. $168 \mathrm{CE}$ ) y en los casos de ratificación de la iniciativa autonómica, aprobación y reforma de los Estatutos de Autonomía de los territorios que accedieran al autogobierno por la vía del artículo $151 \mathrm{CE}$ (arts. 151.1, 151.2.3ำ y 152.2 CE); el referéndum facultativo a petición de una décima parte de diputados o senadores en el procedimiento ordinario de reforma constitucional (art. 167 CE), y el referéndum consultivo para decisiones políticas de especial transcendencia, cuya iniciativa se atribuyó solo al presidente del Gobierno y su convocatoria fue supeditada a la autorización del Congreso (art. $92 \mathrm{CE})^{61}$. Así las cosas, el papel de los ciudadanos quedó reducido a ratificar acuerdos ya adoptados por las instituciones representativas como requisito para su perfección normativa (arts. 168, 151.2.3 y 152.2 CE), a arbitrar entre la mayoría parlamentaria que apruebe una reforma constitucional ordinaria y la minoría de una décima parte de diputados o senadores que discrepe de ella (art. 167 CE) y a plebiscitar decisiones políticas que el presidente del Gobierno decida someter a consideración popular (art. $92 \mathrm{CE}$ ). Cualesquiera otros sujetos proponentes, como las Cámaras, varias CCAA o un número acreditado de electores mediante iniciativa popular, a los que el artículo 85.2 del anteproyecto de Constitución elaborado por la Ponencia otorgaba legitimación, fueron tajantemente descartados.

Como consecuencia de tan restrictiva regulación —que la Ley 3/1980, de 18 de enero, agudizó-, y del tradicional recelo de nuestra clase política hacia esta figura, el referéndum ha sido poco usado. Al margen de los referéndums para la aprobación de la CE y para la aprobación y reforma de los Estatutos de Autonomía elaborados de conformidad con el artículo 151.2 CE, en España sólo se han realizado dos referéndums de carácter consultivo y de ámbito nacional: el referéndum de 12 de marzo de 1986 para someter a la consideración del pueblo español la pertenencia de España a la OTAN y el referéndum para la aprobación del Tratado de Lisboa, de 20 de febrero de 2005.

En contraste con este pobre balance, en el período comprendido entre 1995 y 2019, se han celebrado en otros países europeos (Italia, Irlanda, Suiza, Reino Unido, Alemania o Países Bajos) más de doscientos referéndums de índole diversa y a iniciativa de distintos sujetos legitimados: sobre reforma constitucional, reformas institucionales y electorales, cesión de poderes a organizaciones internacionales o definición

60 ALZAGA VILLAAMIL, O. (2012). «Presentación de la encuesta sobre referéndum», Teoría y realidad constitucional, 30, p. 11.

61 Sobre el marco constitucional del referéndum, CRUZ VILLALÓN, P. (1980). «El referéndum consultivo como modelo de racionalización constitucional», Revista de Estudios Políticos, 13, pp. 145-168; OLIVER ARAUJO, J. (1989). «El referéndum en el sistema constitucional español», Revista de Estudios Políticos, 29, pp. 115-184 y PÉREZ SOLA, N. (1994). La regulación constitucional del referéndum, Jaén, Universidad de Jaén, p. 137-184. 
de políticas públicas. Los resultados de algunos de estos referéndums, particularmente de los celebrados a partir de 2015, han suscitado, sin embargo, cierta polémica, como el referéndum sobre las condiciones del rescate de la economía griega, el brexit británico o los referéndums sobre las cuotas de refugiados y sobre el acuerdo de cooperación entre la UE y Ucrania, celebrados, respectivamente, en Hungría y Países Bajos. Y ello ha reavivado las críticas hacia la democracia directa y ha evidenciado que los referéndums no son la panacea democrática y que su empleo suscita algunos riesgos que parecen dar la razón, a la postre, al cicatero constituyente español y a sus recelos hacia la democracia directa.

Es indudable que, como Tierney ha subrayado ${ }^{62}$, la llamada a la participación directa en un referéndum no excluye la mediación y el control del proceso decisorio por las élites, puesto que la opinión pública a consultar se forma y articula por la acción de los partidos, de los grupos de presión y de los medios de comunicación (the elite control syndrome). En los procesos de referéndum existe además la tendencia a agregar prejuicios, o a expresar emociones, en lugar de formar opiniones racionales a través de la deliberación (the deliberation deficit). Los referéndums, en fin, conforman mayorías en torno a una opción simplificada, normalmente bipolar, anulando las posiciones alternativas al respecto y toda posibilidad de agregación de intereses individuales (the majoritarian danger). Desde este punto de vista, pueden ser un peligro para las minorías, cuyos derechos y libertades fundamentales pueden verse afectados. Pero estos riesgos también están presentes en los procesos electorales y en el funcionamiento ordinario de las instituciones representativas. «No hay — afirma Tierneyuna evidencia que demuestre que un referéndum, por definición, es más abierto a la manipulación de las élites que unas elecciones», porque toda votación popular requiere mediaciones y es precisamente la concurrencia e implicación de los partidos y de los medios en el proceso electoral lo que permite inducir y expresar la voluntad general $^{63}$. Tampoco puede afirmarse con rotundidad que sólo las elecciones y las instituciones representativas garantizan una deliberación informada. Para participar en los procesos electorales no se exige a los ciudadanos que se informen sobre los programas de los partidos y deliberen. Y en la mayoría de las ocasiones, la justificación y el sentido del voto de los representantes en sede parlamentaria no están determinados por la deliberación racional, sino por la disciplina partidaria. Por último, respecto al respeto de las minorías, que, según algunos autores ${ }^{64}$, es la principal objeción contra el referéndum, tampoco la democracia representativa está libre de abusos de la regla de la mayoría; máxime, cuando es la regla de la mayoría simple la que rige la generalidad de la toma decisiones parlamentarias, exigiéndose mayorías reforzadas o más amplios acuerdos sólo en determinados casos.

62 TIERNEY, S. (2012). Constitutional Referendums. The Theory and Practice of Republican Deliberation, OxfoRD Constitutional Theory, p. 23.

63 Ibidem, p. 128.

64 QVORTRUP, M. (2002). A Comparative Study of Referendums: Government by the People, New York, Manchester University Press, p. 158. 
La mediatización de las elites, la simplificación populista y el abuso de las mayorías no son, por tanto, males privativos de la democracia directa. Y para prevenirse frente a ellos la solución no es vetar la participación inmediata de los ciudadanos en las decisiones colectivas y bloquear el referéndum, puesto que seguirían presentes, sino garantizar constitucionalmente los derechos de las minorías y multiplicar, precisamente, los canales de participación/decisión popular mediante una regulación rigurosa y garantista de las diversas modalidades de referéndum, como han decidido hacer varios países europeos y propugna un sector de la doctrina en España.

\section{LAS MODALIDADES DE REFERÉNDUM CUYA INCORPORACIÓN COMPLEMENTA Y CONTRAPESA LA DEMOCRACIA REPRESENTATIVA. LA PLURALIDAD DE SUJETOS LEGITIMADOS PARA INSTAR SU CONVOCATORIA}

Con las cautelas procedimentales y materiales debidas, el referéndum puede ser un complemento eficaz de la democracia representativa y un correctivo útil que incidiría en la determinación de los tiempos y contenidos de la actividad parlamentaria. El referéndum puede utilizarse para ratificar o legitimar las grandes decisiones políticas, como los supuestos de reforma constitucional o la delegación de poderes a autoridades internacionales, y puede servir para descargar de responsabilidad al Parlamento en aquellas decisiones críticas, denominadas por Schneider «decisiones de nuevo tipo», cuyo alcance e irreversibilidad comprometen a las generaciones futuras ${ }^{65}$. Pero el referéndum puede ser usado, además, como mecanismo de estímulo y de control de la acción legislativa del Parlamento. En este ámbito, el referéndum puede contribuir a ajustar las decisiones legislativas a las demandas de los ciudadanos y operar como instrumento de veto del predominio parlamentario a modo de eficaz contrapeso del entramado institucional ${ }^{66}$. El referéndum legislativo puede ser útil en una doble perspectiva: una potencialmente positiva o propositiva, encaminada a dinamizar la relación representativa y enfrentar la pasividad o la resistencia de los legisladores hacia materias concretas, y otra de carácter negativo o reactivo, consistente en controlar y compensar los procesos parlamentarios de formación de la ley.

En España, el referéndum es un mero instrumento de legitimación en manos del presidente del Gobierno (art. $92 \mathrm{CE}$ ) y de estabilidad y rigidez constitucional (arts. 167 y 168 CE), pero no aporta nada más, ni desempeña las aludidas funciones de estímulo y contrapeso de la democracia representativa. Debido a ello, parte de la doctrina propone su revisión constitucional, incorporando a nuestro ordenamiento el referéndum sobre propuestas normativas surgidas a iniciativa popular, como posibilitaba el

65 SCHNEIDER, H. P. (1991). «Soberano sin poder. Representación y participación del pueblo como problema de legitimación de la soberanía democrática», en Democracia y Constitución, Madrid, CEC, p. 260.

66 LUCIANI, M. (2008). «El referéndum, cuestiones teóricas y de la experiencia italiana», Revista Catalana de Dret Public, 37, pp. 9-12. 
artículo 66 de la Constitución de 1931, y también los referéndums sobre leyes votadas y aún no sancionadas y los abrogatorios de leyes en vigor, modalidades que preveía el artículo 85 del anteproyecto de Constitución elaborado en $1977^{67}$.

Con funcionalidad positiva, la experiencia comparada avala el referéndum propositivo de normas a iniciativa de un número de ciudadanos, a quienes se reconoce la facultad de presentar una propuesta legislativa o constitucional para que sea votada directamente por el cuerpo electoral o para que se debata en el Parlamento y, en el supuesto de ser rechazada, sea sometida a referéndum. La iniciativa popular sobre materias constitucionales posibilita a los ciudadanos proponer directamente modificaciones de la Constitución, sin intermediación de sus representantes, cuya resistencia o pasividad la ciudadanía puede así sortear. Por su parte, la iniciativa legislativa ciudadana permite plantear la regulación legislativa de cuestiones sobre las que los representantes se desentienden, o directamente rechazan, y lograr su aprobación mediante la apelación directa al cuerpo electoral. Ambas modalidades están previstas en varios Estados de EE.UU., donde, en unos casos, las propuestas se someten directamente a votación popular y, en otros, son remitidas a las legislaturas y, de no ser asumidas por los parlamentarios en un plazo determinado, deben someterse a referéndum. También ambas están reguladas en la totalidad de los Länder alemanes, cuyos parlamentos deben pronunciarse sobre las iniciativas propositivas presentadas. En el caso de ser aceptadas, las iniciativas articuladas quedan aprobadas y el referéndum no se celebra. De introducirse enmiendas o de resultar rechazadas, las iniciativas deben someterse a referéndum, pudiendo algunos Landtag redactar una propuesta alternativa o contraproyecto que se vota junto con la iniciativa popular. Suiza sólo prevé con perfil propositivo los referéndums de revisión total o parcial de la Constitución federal, pero varios cantones incorporan el referéndum propositivo de leyes. Francia incorporó en 2008 el referéndum propositivo de iniciativa compartida entre una quinta parte de los miembros de la Asamblea Nacional y una décima parte de los electores (art. 11 de la Constitución). Y también han incorporado en los últimos años la posibilidad de celebrar referéndums propositivos las regiones italianas con estatutos de segunda generación (Calabria, Campania, Cerdeña, Friuli-Venecia Julia, Lacio y Valle de Aosta), en el caso de que las iniciativas legislativas de los ciudadanos no sean examinadas por el Consejo regional en un plazo determinado o si resultan rechazadas $^{68}$.

Los referéndums sobre leyes votadas y aún no sancionadas y los abrogatorios sobre leyes en vigor también están extendidos en derecho comparado y su función correctora

${ }^{67}$ Por todos, CASTELLÀ ANDREU, J. Ma . (2016). «El referéndum en la Constitución: ¿es necesario un replanteamiento de la institución?», cit., pp. 257-261; REQUEJO RODRÍGUEZ, P. (2014). «El referéndum consultivo en España: reflexiones críticas y algunas propuestas de futuro», cit., pp. 281-282; DÍAZ REVORIO, F. J. (2018). «Democracia, representación y participación ciudadana. A la búsqueda de un equilibrio que la Constitución no logró», cit., p. 267; SÁENZ ROYO, E. (2018). El referéndum en España, cit., pp. 148-154.

${ }_{68}$ GARRIDO LÓPEZ, C. (2019). «La iniciativa popular de referéndum», cit., pp. 320-326.

(C) UNED. Revista de Derecho Politico

N. ${ }^{\circ} 112$, septiembre-diciembre 2021, págs. 139-173 
y de contrapeso de la actividad parlamentaria resulta de primer orden, en la medida en que posibilitan el ejercicio de una suerte de «facultad de veto» del cuerpo electoral sobre la actividad legislativa. La primera modalidad, consistente en la ratificación o suspensión de textos votados en el Parlamento, fue constitucionalizada en Suiza en 1874 bajo la denominación de referéndum facultativo y su convocatoria procede si lo solicitan 50.000 electores u ocho cantones en un plazo de 100 días desde la publicación de la Ley o disposición federal (art. 141 de la Constitución). También está prevista en Irlanda, a iniciativa conjunta de la mayoría del Senado y de un tercio de los miembros de la Cámara de representantes (art. 27 de la Constitución); en Dinamarca, a propuesta de un tercio del Parlamento (art. 42.7 de la Constitución); en Francia, a propuesta del Gobierno o de forma conjunta por ambas cámaras (art. 11, primer párrafo); y en varios Estados de EE.UU., a petición de un porcentaje del cuerpo electoral. La segunda modalidad, en la que una Ley en vigor puede ser abrogada total o parcialmente mediante referéndum, está prevista en varios países europeos y en un buen número de países latinoamericanos (Uruguay, Venezuela, Colombia, Ecuador y Costa Rica, entre otros). En Italia, donde más referéndums abrogatorios se han celebrado a nivel nacional, la iniciativa corresponde a 500.000 electores o a cinco consejos regionales y no puede afectar a leyes tributarias y presupuestarias, de amnistía e indulto, ni de autorización para ratificar tratados internacionales (art. 75.2 de la Constitución). Y en Alemania, varios Länder (Berlín, Bremen, Mecklemburgo-Prepomerania, Baja Sajonia, Sarre y Sajonia-Anhalt) reconocen la iniciativa de referéndum para la modificación o derogación de leyes a un número absoluto de votantes o a un porcentaje del cuerpo electoral, según los $\operatorname{casos}^{69}$.

El referéndum facultativo sobre normas, en sus modalidades propositiva, suspensiva y abrogatoria, representa un estímulo o acicate para la búsqueda continuada del compromiso entre las fuerzas políticas y entre estas y las organizaciones de la sociedad civil. El referéndum facultativo estimula la receptividad de los representantes a las demandas ciudadanas y resulta políticamente integrador. Y puede funcionar, llegado el caso, como correctivo de la inactividad legislativa (en su modalidad propositiva) y del predominio y las disfuncionalidades parlamentarias (modalidades suspensiva y abrogativa): un correctivo que canalice e integre el descontento mediante la implicación popular en el proceso legislativo y la generación de una dinámica consensual.

Todas estas modalidades de referéndum contribuyen a reforzar el vínculo representativo y la legitimidad de la ley, sobre todo si el constituyente amplía la legitimación para instar su convocatoria a varios entes subcentrales, a la minoría parlamentaria o a un número o porcentaje de ciudadanos. Cuando los gobiernos o las mayorías parlamentarias controlan el referéndum tienden a usarlo para reforzar su posición de poder y a fin de doblegar la resistencia y los contrapesos de otras instituciones democráticas. A mayor número de sujetos proponentes, en cambio, la

69 SÁENZ ROYO, E. (2016). «La regulación del referendo en el derecho comparado: aportaciones para el debate en España», Revista Española de Derecho Constitucional, 108, pp. 132-135. 
tentación de utilización plebiscitaria del referéndum se reduce y su funcionalidad democrática aumenta, porque suma un poder corrector al sistema. De ahí la importancia de la ampliación de los sujetos legitimados para instar su convocatoria.

El reconocimiento de la iniciativa de referéndum a los entes subcentrales de autogobierno persigue lograr una mayor integración de los intereses territoriales en la voluntad general y moderar las tendencias centralizadoras de la mayoría parlamentaria nacional. Suiza la otorga a ocho cantones en los referéndums propositivos; Italia, a cinco regiones para instar referéndums abrogatorios. Y en España, el anteproyecto de Constitución elaborado por la ponencia en 1977 otorgaba legitimación para los referéndums legislativos previstos a las asambleas de, al menos, tres CC.AA. El reconocimiento de la iniciativa a una minoría parlamentaria posibilita, por su parte, oponer un contrapeso a las decisiones de la mayoría y estimular la negociación entre los grupos. En Dinamarca, un tercio del Folketing posee esta iniciativa; y también está prevista en varios Länder alemanes y en varios Estados latinoamericanos. Más generalizado en el derecho comparado es el reconocimiento de la iniciativa popular de referéndum o vinculada al referéndum. Y en los lugares donde existe, la acción legislativa y de gobierno tiende a acercarse más a las preferencias de los votantes que en donde no se reconoce y se incorporan asuntos a la agenda parlamentaria que no figuraban con anterioridad o no eran recogidos por los grupos políticos. La posibilidad de activar la iniciativa popular para la celebración de referéndums estimula la receptividad de los representantes y la negociación entre los actores políticos. Una vez formalizada la iniciativa, las opciones de integración de las demandas ciudadanas continúan abiertas en sede parlamentaria, tanto si las iniciativas son propositivas, como si son abrogatorias. Y si, pese a las oportunidades abiertas a la negociación, finalmente el referéndum a instancia popular es convocado, los ciudadanos pueden pronunciarse sobre cuestiones que los representantes han omitido abordar y sobre la aceptación o rechazo que su actividad legislativa suscita, operando de este modo como garantía de cierre del sistema y mecanismo de equilibrio institucional ${ }^{70}$.

Atendiendo a su funcionalidad, los miembros de la ponencia reconocieron en el anteproyecto de Constitución de 1977 la iniciativa para someter a referéndum derogatorio de leyes a tres asambleas de territorios autónomos y a 750.000 electores, y para ratificar en referéndum leyes votadas y no sancionadas, a tres asambleas autonómicas (art. 85), pero dichas previsiones fueron eliminadas en su tramitación parlamentaria posterior. Y en el mismo sentido, la Junta General del Principado de Asturias aprobó y presentó en el Congreso de los Diputados el 14 de octubre de 2014 su proposición de reforma constitucional de los artículos 87.3, 92 y $166 \mathrm{CE}$, que reconocía la iniciativa a 500.000 electores tanto para los referéndums consultivos como para la modalidad de referéndums derogatorios de las leyes que la propuesta

70 GERBER, E. R. (1996). «Legislative Response to the Threat of Popular Initiatives», cit.,

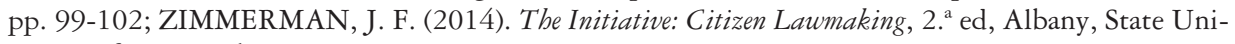
versity of New York Press, pp. 129-155.

(C) UNED. Revista de Derecho Politico

N. ${ }^{\circ} 112$, septiembre-diciembre 2021, págs. 139-173 
incorporaba. Tras sucesivas disoluciones de las Cortes Generales, la importante proposición de reforma, trasladada de Legislatura en Legislatura, sigue pendiente de su toma en consideración y continúa sin celebrarse el preceptivo y necesario debate parlamentario sobre el posible impulso de la democracia directa en nuestro país.

\section{CONSIDERACIONES FINALES}

La democracia representativa enfrenta una seria crisis de legitimidad. La ola de indignación producida durante la recesión económica llenó las calles de manifestantes y dio lugar a movimientos sociales y nuevos partidos que cuestionaron las instituciones representativas y su modo de adoptar decisiones. Aquella indignación y sus propuestas de regeneración política pueden quedar en un desahogo improductivo o alimentar peligrosos populismos, pero, canalizadas institucionalmente, también pueden ser un revulsivo que regenere la democracia, permita la agregación de intereses y fortalezca la capacidad de integración del sistema político. Para lograrlo, es preciso mejorar el funcionamiento de las instituciones representativas, que son la clave de bóveda del sistema, reformar el sistema electoral y garantizar la democracia interna de los partidos. Pero como complemento y acicate de esa mejora, cabe posibilitar e incentivar la participación popular en alguna, o en todas, las fases del proceso de formación de la voluntad general: en el arranque del procedimiento legislativo (mediante la reforma de la iniciativa legislativa popular), en su transcurso (incorporando a los procedimientos parlamentarios las audiencias y comparecencias ciudadanas), a su término, ratificando o derogando su resultado (referéndums legislativos de ratificación y abrogatorios) o, al margen del mismo, sobre cuestiones de especial trascendencia política o sobre posibles proposiciones de Ley que, ampliando los sujetos legitimados, se sometan a consulta del cuerpo electoral (referéndums consultivos y propositivos). Estas reformas, como Rosanvallon ha subrayado ${ }^{71}$, permitirían completar la democracia de elección, en la que el pueblo limita su participación a la emisión del voto, con una «democracia de expresión», «de implicación» y «de intervención», en la que el ciudadano forma su opinión, se vincula con otros y emprende una acción colectiva para incidir en el proceso de formación de la voluntad general.

La democracia directa y participativa no constituye una alternativa a la democracia representativa. Y tampoco es una amenaza para la estabilidad y la legitimidad parlamentarias, ni debilita la función de integración de los partidos, como sostienen sus críticos. En la actualidad, las propuestas participativas de profundización democrática han aceptado el protagonismo de la representación política, plural y de partidos en el Estado constitucional. Y asumen que los principios de representación y mayoría son recursos imprescindibles para el funcionamiento del gobierno en las

71 ROSANVALLON, P. (2007). La contrademocracia. La política en la era de la desconfianza, Buenos Aires, Manantial, p. 36. 
democracias de masas. Dichos recursos, sin embargo, «no pueden convertirse en la característica esencial del concepto de democracia y desplazar la verdadera esencia: la consecución de la colaboración participativa de todos los ciudadanos en la formación de la voluntad estatal» ${ }^{72}$, por lo que las estructuras de las democracias representativas deben incorporar instrumentos que permitan la participación e implicación popular. El objetivo de esos instrumentos debe ser, como sostuvo Bobbio, lograr la articulación de la participación directa con la participación a través de representantes en «un sistema de democracia integral» que «puede abarcar a las dos formas de participación, cada una de acuerdo con las diversas situaciones y las diferentes necesidades, porque son, en cuanto adaptables a diversas situaciones y a diferentes necesidades, perfectamente compatibles» ${ }^{73}$. El debate hoy, por tanto, no debiera consistir en enfrentar la democracia representativa con la democracia directa, sino, dada su compatibilidad, en determinar en qué medida y bajo qué fórmulas la actual democracia parlamentaria puede incorporar a sus esquemas institucionales los instrumentos de la democracia inmediata. Un dilema que España debería resolver impulsando constitucionalmente la democracia directa y participativa, porque en la actual situación crítica del paradigma representativo puede jugar un papel fundamental descargando la presión sobre las instituciones representativas y contribuyendo a la integración y legitimación democráticas. A tal efecto, cabría potenciar los mecanismos de participación ciudadana en los procedimientos parlamentarios de elaboración de la Ley introducidos en algunas asambleas autonómicas. Y considerar, como aquí se ha postulado, la incorporación a nuestro ordenamiento de la iniciativa legislativa ciudadana reforzada por su vinculación al referéndum en los supuestos de rechazo o de contrapuesta parlamentaria, así como la constitucionalización de la iniciativa popular de reforma constitucional y del referéndum abrogatorio de leyes, formas de participación directa que fueron previstas en el anteproyecto de Constitución y que la proposición de reforma constitucional de la Junta General del Principado de Asturias pretendía recuperar. El preterido trámite de toma en consideración de dicha proposición sería un buen momento para debatir sobre estas cuestiones en sede parlamentaria. Es lo menos que merece el alcance y la importancia de esta iniciativa autonómica de reforma constitucional, la primera presentada al amparo del artículo 166.1 de la CE.

72 SCHNEIDER, H. P. (1991). «Soberano sin poder. Representación y participación del pueblo como problema de legitimación de la soberanía democrática», cit., p. 250.

${ }_{73}$ BOBBIO, N. (1986). El futuro de la democracia, México, Fondo de Cultura Económica, pp. 60-61.

(C) UNED. Revista de Derecho Politico

N. ${ }^{\circ} 112$, septiembre-diciembre 2021, págs. 139-173 
Title:

Crisis of the Representative Model and Proposals to Promote Direct Democracy.

\section{Summary:}

1. ECONOMIC RECESSION AND LEGITIMACY CRISIS OF REPRESENTATIVE DEMOCRACY. 2. CAUSES OF THE CRISIS OF THE REPRESENTATIVE MODEL. 2.1. Breach of the social contract and indignant democracy. 2.2. Representation without represented: the lack of receptiveness of representatives. 2.3. Distortions in the configuration and update of representation. 2.3.1. Electoral system and inequality of representation. 2.3.2. Representativeness and oligarchic functioning of political parties. 2.4. Constraining regulation of the forms of direct democracy in the Spanish constitutional system. 3. PROPOSALS TO PROMOTE THE FORMS OF DIRECT AND PARTICIPATORY DEMOCRACY IN THE ACADEMIC LITERATURE AND IN THE 10TH TERM OF THE SPANISH PARLIAMENT. 4. CITIZENS' LEGISLATIVE INITIATIVE AS A PARTICIPATION INSTRUMENT. 4.1. Failure and required revision of the citizens' initiative. 4.2. Reduction in the number of signatures required and in the matters excluded from the citizens' initiative. A bid for the citizens' initiative linked to the referendum. 5. USEFULNESS OF THE REFERENDUM IN DIRECT DEMOCRACIES. 6. REGULATION AND LIMITED PRACTICE OF THE REFERENDUM IN SPAIN. ONCE AGAIN THE DEBATE ABOUT ITS RISKS. 7. THE MODALITIES OF REFERENDA THAT COMPLEMENT AND COUNTERBALANCE REPRESENTATIVE DEMOCRACY. THE PLURALITY OF SUBJECTS LEGITIMIZED TO CALL IT. 8. FINAL CONSIDERATIONS.

\section{Resumen:}

La democracia representativa padece una seria crisis de legitimidad. La recesión económica y la ola de indignación generada por la incapacidad del Estado para enfrentarla han cuestionado el paradigma representativo. Y ello ha reabierto el debate sobre la incorporación de nuevas vías de participación de los ciudadanos en las decisiones colectivas, sobre su funcionalidad y sobre su compatibilidad con la democracia representativa. En este contexto, las formas de participación directa han recobrado protagonismo porque, reguladas con las garantías precisas, pueden contribuir a completar la democracia de elección con una mayor implicación e intervención de los ciudadanos en el proceso de formación de la voluntad general.

En España, la regulación de estas formas de participación es muy restrictiva y su balance práctico resulta muy limitado. La situación es muy distinta en otras democracias occidentales, donde la iniciativa popular y, especialmente, el referéndum son instrumentos frecuentes de participación política que operan como complemento y contrapeso de la democracia 
representativa. La regulación y la práctica de la democracia directa en estos países, que en este trabajo analizamos junto a las insuficiencias de la regulación española, pueden servir de modelo para una regulación más incisiva y generosa de estas formas de participación política en una futura, y cada vez más necesaria, reforma de nuestra Constitución.

\begin{abstract}
:
Representative democracy experiences a serious crisis of legitimacy. The economic recession and the surge of indignation resulting from the State's inability to deal with it have casted doubts on the representative model. This, in turn, has reopened the debate on the incorporation of new forms of citizen participation in collective decisions, on their usefulness and on their compatibility with representative democracy. In this context, forms of direct participation have recovered their leading role since they - with the appropriate guarantees - may contribute to complete election democracy with more involvement and intervention of citizens in the formation of the general will.

The regulation of these forms of participation in Spain is highly restrictive, and its practical balance very limited. The situation is quite different in other occidental democracies, where citizens' initiatives - particularly referenda - are normalized instruments for political participation functioning as a complement and counterbalance to representative democracy. The regulation and practice of direct democracy in these countries which this work analyzes together with the deficiencies of the Spanish case- may serve as a model for a more incisive and generous regulation of these forms of political participation in a future and necessary reform of the Spanish Constitution.
\end{abstract}

Palabras clave:

Democracia representativa; iniciativa popular; referéndum.

Key words:

Representative democracy; citizens' initiative; referendum. 